\title{
Blinding Struts - Part 1: Buckling Response
}

\author{
Abela, J.M., Vollum, R.L., Izzuddin, B.A. \& Potts, D.M. \\ Department of Civil and Environmental Engineering \\ Imperial College London, London SW7 2AZ, United Kingdom
}

\begin{abstract}
The term 'blinding' is used to describe the thin layer of unreinforced over-site concrete which is used to protect the base of excavations from construction traffic and to provide a clean surface for the construction of the base slab. Blinding is not generally seen or exploited as a structural element even though it clearly provides some temporary lateral support to the retaining walls of cut-and-cover excavations. This paper shows that enhanced blinding can be used to prop retaining walls in cutand-cover excavations during construction prior to the completion of the base slab. An experimental programme is conducted on $1 / 4$ scale specimens, which demonstrates that the failure load of blinding struts is governed by upheaval buckling, and which is employed for the validation of nonlinear finite element models. The main parameters governing the buckling load are shown to include: i) the amplitude of the geometrical imperfection, ii) the thickness of blinding, and iii) the eccentricity of the applied load with respect to the centroid of the strut.
\end{abstract}

Key words: Upheaval buckling; geometric imperfections; concrete; cut and cover excavations; nonlinear finite element analysis; laboratory testing 
This work was motivated by Powderham's [1] innovative use of blinding struts on major infrastructure projects such as the Channel Tunnel, Limehouse Link and the Heathrow Cofferdam. The thickness of blinding used in these projects ranged from $100 \mathrm{~mm}$ to $500 \mathrm{~mm}$ which is considerably thicker than the 50 to $75 \mathrm{~mm}$ traditionally used for over-site concrete. Blinding struts were typically constructed in the following sequence on these projects:

1. The retaining walls are constructed from ground level using secant piles or other forms (e.g. diaphragm or sheet pile walls).

2. The soil is excavated from between the retaining walls in the raked fashion idealised in Fig. 1 for a cantilever retaining wall. In deeper excavations, the retaining wall may also need to be propped with the roof slab and intermediate props as necessary.

3. The base of the excavation is carefully levelled before the blinding is cast to minimise lateral imperfections due to lack of formation flatness.

4. The blinding is cast and levelled to its specified thickness. In practice, the thickness of blinding varies due to constructional tolerances which induce geometrical imperfections into the strut. These variations in slab thickness need to be carefully controlled within prescribed limits to ensure the strut has adequate strength. Blinding is cast sequentially in strips as the excavation moves forward with the width of each strip being dependent on the stability of the unpropped excavation (Fig. 1).

5. Since the axial load is principally introduced into blinding struts when the ground is excavated ahead of the most recently cast section of blinding [2], 
the concrete needs to gain sufficient strength before the next stage of excavation can be taken forward. The concrete is typically designed to reach its required strength within 18 to 24 hours from casting to maximise the benefit of using blinding struts.

6. Blinding is used to prop the retaining wall until the base slab is cast. During this time the concrete gains strength with time and creeps under sustained load. Geometric imperfections can also increase due to ground heave below the blinding. This heave arises due to i) subsequent excavation after the blinding has been cast and ii) swelling of the soil below the blinding as a result of the time dependent dissipation of excess pore water pressures created as a result of the excavation process.

Powderham's [1] use of blinding struts allowed much of the intermediate steel strutting, which would otherwise have been required, to be eliminated with considerable time savings. This in turn created a safer working environment which enabled these projects to be completed several months before scheduled with considerable savings in cost and materials. Despite their evident advantages, however, blinding struts have not been widely used in practice. This is no doubt partly due to a lack of awareness of their potential strength which is not recognized by code-based methods for designing struts. In addition, Powderham [2] has found some clients unwilling to sanction the use of blinding struts since their behaviour is considered uncertain and not definitively established. This paper demonstrates through tests on $1 / 4$ scale models and accompanying nonlinear finite element analysis that blinding struts can provide considerable compressive resistance. The tests are 
carried out to determine the potential failure modes of blinding struts, which have not been tested to failure previously.

\section{Research scope}

The behaviour of blinding struts is complex and dependent on parameters which are difficult to quantify such as the end restraint provided by the retaining walls, lack of initial ground flatness and subsequent concrete creep and ground heave. This paper focuses on the behaviour of blinding struts under short-term loading. The effects of time dependent ground heave and concrete creep are considered elsewhere [3]. The paper describes a series of $1 / 4$ scale tests and associated nonlinear finite element analyses (NLFEA) that were carried out to investigate the influences of slab thickness, lateral imperfections and end restraint on the short-term failure load of blinding struts. The strength and failure mode of blinding struts is shown to depend on the amplitude and profile of the ground imperfection, the eccentricity of the applied axial load with respect to the centroid of the strut and the vertical restraint provided by the retaining wall. The paper shows that the performance of the tested struts can be accurately predicted with NLFEA, which can thus be used in support of the design of blinding struts. In this respect, NLFEA can either be employed directly for specified geometrical imperfections and end conditions or indirectly for the calibration of simplified design-oriented models as developed in the companion paper [4]. 
Blinding struts can potentially fail due to localised concrete crushing or buckling. Fig. 2 illustrates that blinding struts are constrained to buckle upwards against their self-weight, and that the buckle wavelength is not clearly defined. The behaviour illustrated in Fig. 2 is an example of upheaval buckling which has been widely researched in the context of thermally induced buckling of railway tracks $[5,6]$, concrete pavements $[7,8]$ and deep sea pipelines [9-11]. Upheaval buckling is most simply explained with reference to Croll's clamped column analogy $[6,7,10,11]$, which is particularly relevant to the design of blinding struts since it makes allowance for the effects of geometric imperfections. According to this approach, the propagation load $P_{p}$ for a buckle of amplitude $w^{\prime}$, relative to its lift off points, and length $L_{p}$ in an infinitely long pipeline can be approximated as:

$P_{p}=P_{c}\left(1-\frac{\xi}{w^{\prime}}\right)$

where $P_{c}$ is the Euler buckling load for a clamped column of length $L_{p}$, elastic modulus $E$ and second moment of area $I,\left(P_{c}=\frac{4 \pi^{2} E I}{L_{p}^{2}}\right)$ and $\xi=w_{g}-W_{L}$ is the difference between the geometric $\left(w_{g}\right)$ and gravity loading $\left(w_{L}\right)$ imperfections, with the loading imperfection defined as:

$$
w_{L}=\frac{q L_{p}^{4}}{384 E I}
$$

where $q$ is the self weight of the strut per unit length.

Equation (1) implies that an initially perfectly straight strut with $w_{g}=0$ will never buckle since $w^{\prime}=0$ prior to uplift. This raises the question of why struts buckle upwards in the first place. The answer lies in the observation that real struts are 
unlikely to be perfectly straight. Furthermore, even perfectly straight struts buckle if the axial load is applied below the centre line of the strut as shown in Fig. 3a or above the centreline as shown in Fig. 3b. The initial uplift axial load of the imperfect struts shown in Fig. 2 depends on the length and amplitude of the ground imperfection. After initial uplift, the amplitude and wavelength of the buckle depends upon the magnitude of the axial load. The buckle propagates outwards from the lift off points with increasing amplitude as the axial load is increased, until the critical buckle length is reached and failure occurs.

Croll [11] used equation (1) to derive simplified expressions for the critical buckling load of an infinitely long elastic strut that is draped over a sinusoidal imperfection with amplitude $w_{g}$ and length $L_{g}$. Croll [11] showed that the buckle propagation load $P_{p}$ corresponding to a specific buckle amplitude $w^{\prime}$ is determined from equation (1) by a propagating buckle length $L_{p}$ which minimises $P_{p}$. He went on to show that the least critical buckling load $P_{b}$ occurs for a so called empathetic imperfection with amplitude equal and opposite to the downward deformation of a clamped beam of the same length subject to self-weight (i.e. if $w_{g}=w_{L}$ when $w_{L}$ is calculated according to equation (2) with $L_{p}=L_{g}$ ). Croll [11] showed that the critical buckling load is less for a strut that is cast onto an imperfection (i.e. unstressed when initially draped over the imperfection) than for an otherwise identical strut that is unstressed when straight. The least critical buckling load $P_{b}$ of a strut that is cast on an empathetic imperfection is given by:

$$
\begin{aligned}
& P_{b}=\frac{4 \pi^{2} E I}{L_{p o}{ }^{2}} \\
& L_{p o}=\sqrt[4]{\frac{384 E / W_{g}}{q}}
\end{aligned}
$$


The key differences between upheaval buckling in blinding struts and railway tracks or deep sea pipelines are as follows: i) the axial load is transferred into blinding struts from the retaining walls rather than from restrained thermal expansion, ii) the buckle length is limited by the excavation width, and iii) concrete is much weaker in tension than compression. Furthermore, concrete gains strength rapidly after casting and creeps with time under sustained load. Consequently, Croll's analysis is of limited applicability to the design of blinding struts where i) end conditions are important and ii) short imperfections with $L_{g}<L_{p o}$ can be critical due to the effects of cracking as discussed in the companion paper [4]. It follows that empathetic imperfections, while typically critical for railway tracks and pipelines, are not generally critical for blinding struts.

\section{$4 \quad$ Nonlinear finite element analysis of blinding struts}

Nonlinear finite element analysis (NLFEA) was used to design the tested slabs and to investigate the potential influence of variations in slab thickness, end restraints and imperfection geometry. The analyses were carried out with the NLFEA program ADAPTIC [12] developed at Imperial College. However, any commercially available NLFEA program could be used provided that it handles geometric nonlinearity, deals with contact analysis and incorporates a suitable material model. The strut is discretised with cubic elasto-plastic 2D beam-column elements incorporating both geometric and material nonlinearities [13]. These elements are connected to the soil with joint elements modelling contact behaviour [12,14], as shown in Fig. 4, where the soil is assumed to be rigid with no cohesion. The joint elements were rigid in compression and had zero tensile resistance. The strut is initially loaded with its self- 
weight before being loaded to failure with an axial load $P$ which is applied through a rigid link element of variable length (see Fig. 4) to simulate the end eccentricity measured in the tested slabs.

The nonlinear concrete material model con1 [14] (see Fig. 5) was used for all the analyses presented in this paper. The initial compressive response in Fig. 5 is quadratic. The tensile softening stiffness was related to the element length using the concept of fracture energy with the coefficient of fracture energy calculated in accordance with Model Code 90 [15]. The measured and predicted responses of the tested struts are presented together in the next section for ease of comparison.

\section{Description of short-term loading tests}

Tests were carried out on $1 / 4$ scale models of blinding struts to investigate the effect of varying the strut thickness, imperfection profile and loading eccentricity. The test results are used firstly to demonstrate the potential of blinding to act as struts in cut-and-cover excavations and secondly to validate the numerical analysis. The test specimens were designed to simulate the behaviour of blinding struts spanning $20 \mathrm{~m}$ at $1 / 4$ scale. The key decisions in dimensioning the test specimens were the choice of ground profile, strut thickness and imperfection amplitude. Geometrical imperfections arise in blinding struts due to initial lack of ground flatness and subsequent ground heave. Croll's analysis $[10,11]$ implies that an imperfection formed by initial lack of ground flatness is more critical for elastic upheaval buckling than a geometrical imperfection of the same size and shape formed by ground heave. Consequently, the blinding is assumed to be initially unstressed when laid over the geometrical imperfection, even when heave is considered, since this gives a lower bound on the critical elastic buckling load. It should be noted that a strut which is 
initially straight and subject to subsequent ground heave can be more critical if failure occurs well before the buckling load by crushing of the concrete in combined flexure and axial load, though for practical struts this is not typically the case. The tests investigated the effect of varying the shape and amplitude of the ground imperfection on the buckling load. The profile was chosen to be either sinusoidal with length equal to the strut length or to follow the incremental heave profile calculated in a threedimensional geotechnical analysis obtained using ICFEP [16], termed hereafter the ICFEP profile. The amplitude of the initial imperfection was based on Powderham's [2] observation that ground imperfections would not exceed $\pm 50 \mathrm{~mm}$ if due care is taken in the preparation of the ground formation.

The tested specimens measured $5 \mathrm{~m}$ long by $500 \mathrm{~mm}$ wide with thicknesses varying between $50 \mathrm{~mm}$ and $68 \mathrm{~mm}$. The amplitude of the sinusoidal imperfection was taken as either $6.3 \mathrm{~mm}$, which is close to the empathetic amplitude, calculated with equation (2), for a $50 \mathrm{~mm}$ thick strut with imperfection length $\mathrm{L}_{\mathrm{g}}=5 \mathrm{~m}$ and elastic modulus $E=30 \mathrm{GPa}$, or $8.8 \mathrm{~mm}$. Consideration of equation (1) shows that the imperfection amplitude needs to be scaled by the square of the scaling factor for the specimen dimensions to maintain the same failure stress in the model and full size specimens. It follows that a $50 \mathrm{~mm}$ thick strut with a sinusoidal imperfection of amplitude $6.3 \mathrm{~mm}$ simulates a $200 \mathrm{~mm}$ thick blinding strut spanning $20 \mathrm{~m}$ with imperfection amplitude of $100 \mathrm{~mm}$, which is considered to be an upper bound to the maximum imperfection likely to arise in practice due to the combined effects of lack of flatness and ground heave. It was not considered practical to test slabs with smaller imperfections than $6.3 \mathrm{~mm}$ due to difficulties in controlling the amplitude of the imperfection in the test bed and the as-cast slab thickness. 


\subsection{The test rig}

The rig (see Figs. 6a-d) consisted of an internal reaction frame with a hydraulic jack mounted at one end. The specimen was cast onto a test bed fabricated from two $254 \times 75 \mathrm{~mm}$ structural steel channel sections welded together to make a $508 \mathrm{~mm}$ wide section as shown in Fig. 6b. Six transverse members were welded to the test bed as shown in Fig. $6 \mathrm{~b}$ for vertical support. The transverse members were positioned on plan at each of the six pairs of vertical supports shown in Fig. $6 \mathrm{c}$ which were secured to the ground by means of $50 \times 50 \times 5 \mathrm{~mm}$ SHS rails bolted to the laboratory strong floor. The test bed was deformed into the specified initial imperfection by means of pushing and pulling on the transverse members at the four intermediate supports. A sheet of plywood was fixed to the top surface of the channels to eliminate the minor distortions introduced into the profile by welding. The test bed profile was fine tuned to within $\pm 0.5 \mathrm{~mm}$ of the specified profile by sanding the layer of plywood fixed to the channels. The profile of the test bed was measured with a combination of precise levelling and measurements from displacement transducers (LVDT's and potentiometers) for direct input into the numerical models. Nonlinear finite element analyses with ADAPTIC $[12,14]$ showed that the test bed was sufficiently rigid to provide a rigid foundation to the strut being tested.

The concrete was cast onto a polythene layer to minimise the effects of friction with the test bed. Externally mounted shaker vibrators were used to compact the concrete since the specimens were too thin for poker vibrators to be used. The top surface of the slab was trowelled to a smooth surface and covered with polythene for curing. The surface profile of the as-cast surface was determined with precise levelling. 


\subsection{Concrete material properties}

The concrete mix was designed to have a target compressive strength of $30 \mathrm{MPa}$ at 14 days. Table 1 gives the concrete material properties which were used in the NLFEA for each slab. The concrete strengths were determined at the time of testing the slabs from control specimens cured alongside the slabs. The tensile strengths were derived from split cylinder tests. The concrete elastic moduli in Table 1 were derived from strain measurements in a) control cylinders cast from the concrete used in each slab or b) from in-situ strain measurements in the slab.

\subsection{Loading procedure and instrumentation}

The strut was loaded uniformly in compression at each end through a roller bearing which was in turn attached to a spherical seating as shown in Fig. $6 \mathrm{~d}$. The axial load was measured with a load cell that was placed between the ram of the actuator and the spherical seating. The axial and transverse displacements of the blinding strut were measured relative to the laboratory floor during loading with transducers typically positioned at the ends, quarter span positions and mid-span of the blinding strut (see Fig. 6d). Transducers were also positioned one eighth of the slab span from each end of the strut in tests $O$ to $Q$, which were cast onto the ICFEP profile [16]. All the transducers were positioned in pairs on opposite sides of the strut.

\subsection{Test results and analysis}

A total of 7 struts $(F, M, O, P, Q, D \& E)$ were tested to failure under short-term loading. The geometric and material properties of the struts are summarised in Table 1 along with the measured and predicted failure loads. Struts $O$ to $Q$ were cast onto the ICFEP profile which is defined in Table 2 . The predicted response was calculated 
with ADAPTIC [12] using the nonlinear material model shown in Fig. 5 with the appropriate material properties for each strut from Table 1.

The tests showed that the failure load was significantly influenced by the eccentricity of the applied axial load, if the ends of the slabs lifted. This observation was confirmed by numerical analysis with ADAPTIC [12] which also showed that the failure load reduced significantly if the load was applied below the centroid of the slab, but was insensitive to the eccentricity if the load was applied above the slab centroid and the ends were restrained from lifting. The ends of the strut were prevented from lifting in Tests $F, M, O, P$ and $Q$ by inserting a timber wedge between the loading plate and each end of the slab as shown in Fig. 7, which inclined the line of thrust slightly downwards. The load was applied slightly above the centroid of the slab to avoid the possibility of the buckling load being reduced due to the mode shown in Fig. 3a.

\subsubsection{Struts with sinusoidal imperfections and ends restrained from lifting}

Test $\mathrm{F}$ was designed to simulate a strut with an empathetic imperfection. The strut was cast over a sinusoidal imperfection of length $5 \mathrm{~m}$ with amplitude $6.3 \mathrm{~mm}$. The as-built slab thickness was $55 \mathrm{~mm}$. The slab profile was notionally identical in Tests $F$ and $M$ but the slab thickness was increased to $68 \mathrm{~mm}$ in Test $M$ (see Table 1). Slab F failed at a load of $240 \mathrm{kN}$ compared with Slab M which failed at $440 \mathrm{kN}$. Both struts failed explosively in upheaval buckling and fractured into several pieces as shown in Fig. 8. It is worth noting that the localised discrete cracks which characterise the failure mode formed post buckling. Therefore, the use of a smeared crack model is accurate up to the peak load as evidenced by the good comparison between 
measured and predicted displacements shown in Fig. 10. Table 1 shows that the measured and predicted failure loads compared very well for struts F and M. Fig. 9 shows the initial imperfections of these struts and compares the measured and predicted displaced shapes just before failure. The displacements were slightly underestimated by the numerical model towards failure. This is likely to be due to small inaccuracies in the modelling of the strut geometry, material properties and boundary conditions, none of which are fully known.

Fig. 10 compares the measured and predicted axial and transverse load displacement responses of slabs F and M. Figs. 10a and 10b show that the measured and calculated axial and transverse displacements compare very favourably throughout the tests. The good correlation between the measured and calculated displacements shows that the response of the tested specimens can be accurately predicted up to failure by NLFEA, provided that the specimen geometry and material properties are accurately modelled. The post-buckling path could not be traced in the tests due to the snap-back axial response characteristic, which means that the static post-buckling response could not be experimentally obtained even with displacement actuator control. This same characteristic is also responsible for the explosive buckling behaviour observed in the tests.

\subsubsection{Struts with heave profile and ends restrained from lifting}

Struts $O$ and $Q$ were tested to investigate the effect of changing the slab profile from sinusoidal to the heave profile calculated in the 3D geotechnical analysis using ICFEP [16]. The tests were designed to investigate the effect of varying the slab thickness and the eccentricity of the applied axial load with respect to the strut 
centroid. Both struts had the same geometrical imperfection but strut $O$ was $54 \mathrm{~mm}$ thick compared with strut $Q$ which was $60 \mathrm{~mm}$ thick. Furthermore, the ends of strut $O$ were pinned whereas the ends of strut $Q$ were prevented from lifting by $G$ clamps which also provided rotational restraint. Details of the tested specimens are given in Table 1, while the ICFEP profile is defined non-dimensionally in Table 2. Strut O failed at $412 \mathrm{kN}$ and strut $\mathrm{Q}$ at $465 \mathrm{kN}$ which compare favourably with the predicted failure loads of $410 \mathrm{kN}$ and $477 \mathrm{kN}$ respectively. Fig. 11 shows the displaced shape of the strut after casting and immediately before failure. Figs. 12 and 13 show the axial displacements and the transverse displacements measured at the eighth points from each end of the strut in Tests $O$ and $Q$. The figures show that the measured and predicted buckling loads agree well, but the numerical model tends to overestimate transverse displacements. Again, the reasons for this are likely to be due to small inaccuracies in modelling the specimen geometry, imperfections, material properties and boundary conditions, all of which are incompletely defined.

\subsubsection{Effect of end reduction}

There is a risk that the cross-sectional area of the strut is reduced adjacent to the retaining wall as a result of the ground formation not being properly trimmed. Test $P$ (see Table 1 ) was designed to investigate the effect of such a reduction in the strut cross-sectional area on its failure load for the ICFEP imperfection profile used in tests $O$ and $Q$. The ends of the strut were tapered by casting the strut onto a wedge at each end as shown in Fig. 14. NLFEA suggested that the insertion of the wedges could increase the buckling capacity to as much as $592 \mathrm{kN}$, due to the upwards shift in the centroid of the applied load, if buckling was not preceded by concrete crushing at the 
ends of the strut. In reality, the strut failed at $412 \mathrm{kN}$ due to concrete crushing at one end of the strut. It follows that care should be taken in the construction of blinding struts to ensure the cross-section is not reduced sufficiently adjacent to the retaining walls to cause bearing failure.

Fig. 15 shows the initial imperfection in strut $\mathrm{P}$ and compares the measured and predicted transverse displacements immediately before failure. The displacements in the tested slab were very small due to the premature end bearing failure. Fig. 16a compares the measured and predicted lateral displacements at the quarter and eighth points of the strut. The axial displacements are compared in Fig. $16 b$.

\subsubsection{Ends allowed to lift: Buckling in a combined cantilever mode}

Struts $D$ and $E$ were cast over sinusoidal imperfections with length $5 \mathrm{~m}$ and amplitude $8.8 \mathrm{~mm}$ as described in Table 1. The strut thicknesses were $52.6 \mathrm{~mm}$ and $50 \mathrm{~mm}$ respectively. These struts failed at loads of $335 \mathrm{kN}$ and $336 \mathrm{kN}$ respectively which were significantly greater than the failure load of $202 \mathrm{kN}$ calculated assuming that the ends of the struts were restrained from lifting. The difference between the measured and predicted loads was eventually explained by the observation that the ends of the blinding strut lifted during the test as the axial load was increased. This caused the struts to buckle in the combined modes shown in Fig. 17, which increased the buckling load above that of a comparable strut in which the ends are prevented from lifting. Strut D failed in a cantilever mode and strut $E$ buckled in the span. Additional numerical analysis, in which the ends of the strut were not restrained from lifting, demonstrated the existence of a combined buckling mode with similar 
transverse displacements and failure loads to those measured in the tests (see Fig. 17). The measured and predicted axial and transverse displacements are shown in Fig. 18 for tests $D$ and $E$. Table 1 shows that the measured and predicted failure loads of struts $D$ and $E$ compare very favourably when the ends of the struts are allowed to lift in the analyses as in the tests.

Notwithstanding this finding, the ends of blinding struts are considered unlikely to lift in reality due to the inwards deflection of the retaining walls which restrains the slab from moving upwards. Therefore, practical blinding struts are unlikely to buckle in combined modes like those shown in Fig. 17.

\subsection{Overview of test results}

The tests showed that the response of blinding struts under axial load can be accurately predicted with NLFEA (see Table 1 ) when the slab profile, end conditions, ground profile and material properties are accurately known, which is unlikely to be the case in reality. The ground profile is particularly difficult to define since it depends on both the lack of initial ground flatness and the subsequent ground heave. Therefore, conservative assumptions need to be made in practice with regard to end restraints, lack of ground flatness and subsequent ground heave. These issues are addressed further in the development of the design-oriented model presented in the companion paper [4].

\section{Parametric studies}

A series of parametric studies are carried out here using the validated NLFEA models to determine the effect of varying the geometry, loading eccentricity and 
rotational end restraint of a full scale $20 \mathrm{~m}$ long blinding strut. The nonlinear concrete stress-strain relationship shown in Fig. 5 was used in all the analyses with $f_{c}=30 \mathrm{MPa}$. The initial concrete tangent modulus $E$ (see Fig. 5) was taken as $32 \mathrm{GPa}$ and the concrete tensile strength was taken as $3.0 \mathrm{MPa}$. The excavation width of $20 \mathrm{~m}$ is chosen to be representative of a typical cut-and-cover excavation. The ground profile is assumed to be i) sinusoidal, ii) parabolic and iii) the heave profile determined from the incremental 3D geotechnical analysis using ICFEP [16]. The imperfection length was assumed to equal the excavation width of $20 \mathrm{~m}$ in all cases.

The parametric studies show that the buckling mode varies with the shape of the geometric imperfection and the loading eccentricity, as shown in Fig. 19. The initial lift-off point is at the centre of the imperfection for concentrically loaded struts cast on sinusoidal and parabolic profiles, but near the ends for struts cast on the heave profile obtained with ICFEP $[3,16]$.

\subsection{Influence of imperfection amplitude and shape, slab thickness and loading eccentricity}

Equation (1) shows that the buckling load depends on the amplitude of the geometric imperfection. This is illustrated in Fig. 20a which shows the effect of varying the amplitude and shape of the ground profile for a $200 \mathrm{~mm}$ thick strut of length $L_{\text {exc }}=20 \mathrm{~m}$ cast onto an imperfection of length $L_{g}=20 \mathrm{~m}$. The buckling load decreased rapidly with increasing imperfection amplitude for all the imperfection profiles considered. Fig. 20b shows the influence of strut thickness on the critical buckling load for all three imperfections shapes with $w_{g}=100 \mathrm{~mm}$, which is equivalent to $6.3 \mathrm{~mm}$ in the tested slabs, and $L_{g}=20 \mathrm{~m}$. The results show that the buckling load 
increases as the thickness of the strut increases due to the increase in self-weight and flexural rigidity. Furthermore, the relative magnitude of the failure load for each ground profile varies with slab thickness. It should be noted that the results for the sinusoidal profile are not affected by the end restraint (pinned or fixed). Consequently, only one line appears in Fig. 20 for the sinusoidal profile. Fig. 20 also shows that the failure load for the strut with a parabolic profile and pinned ends is very close to the least of the lift-off $\left(P_{L}\right)$ and the uniaxial crushing load where $P_{L}$ is given by:

$$
P_{L}=\frac{q L^{2}}{8 w_{g}}
$$

The influence of varying the eccentricity of the axial load was investigated for a $200 \mathrm{~mm}$ thick strut with $w_{g}=100 \mathrm{~mm}$ and $L_{g}=20 \mathrm{~m}$. The results are presented for all three imperfection profiles in Fig. 21 which shows that the ICFEP profile with pinned ends was particularly sensitive to variations in the loading eccentricity with the failure load reducing significantly as the centroid of the load moved towards the bottom of the slab. The geotechnical analysis [3] suggested that the load is likely to be transferred into the slab above the centroid of the slab due to the inwards rotation of the retaining wall as it deflects.

Figs. 20 and 21 also show that the critical buckling load depends on the imperfection shape, and furthermore that the shape of the most critical profile varies with slab thickness and loading eccentricity with the parabolic profile becoming more critical as the strut thickness increases. 
It has been found in practice that the use of blinding struts can significantly reduce construction times in major infrastructure projects. The test results and analyses presented in this paper show that blinding struts can resist significant axial loads before failing in upheaval buckling. It is also shown that the structural response of blinding struts can be accurately described with NLFEA if the ground profile and section properties are known.

The test results show that the buckling load depends on factors including the amplitude and shape of the ground imperfection, the slab thickness, the end restraints provided by the retaining wall, and the eccentricity of the applied axial load. The critical buckling load reduces significantly as i) the amplitude of the ground imperfection increases and ii) the slab thickness reduces. The tests show that the influence of the axial loading eccentricity depends on whether or not the ends of the strut are allowed to lift. The tests combined with the numerical study indicate that the buckling load is relatively insensitive to the eccentricity of the axial load for the sinusoidal and parabolic profiles if the load is applied above the centroid of the slab and the ends of the strut are prevented from lifting. This is not the case for the predicted heave profiles, where the buckling load increases with increasing eccentricity of the axial load above the strut centroid. More significantly, the critical buckling load reduces significantly as the line of thrust moves progressively below the centroid of the slab. However, geotechnical analysis [3] indicates that the retaining wall rotates inwards as it deflects. Consequently, the axial load is likely to be applied above the centroid of the slab. 
The companion paper builds on the experimental and numerical findings of this paper, and proposes a simplified design method which can be used for assessing the axial load capacity of blinding struts, accounting for upheaval buckling, imperfections, concrete cracking and compressive material strength.

\section{Acknowledgements}

The authors would like to thank Alan Powderham for bringing blinding struts to their attention and for his continued support throughout the project. We also wish to acknowledge the financial support of the Engineering and Physical Sciences Research Council (EPSRC) under grant EP/D505488/1. Additionally, the authors would like to thank the technical staff of the Structures Laboratories at Imperial College London, particularly Mr S. Algar, for their assistance with the experimental work.

\section{$9 \quad$ References}

1 Powderham, A. J. (2002) The observational method - learning from projects. Proc. Geotechnical Engineering J. of the Proc. ICE, 155 (1), 59-69.

2 Powderham, A. J. (2006) Personal communication.

3 Abela, J. M., Blinding struts in cut and cover excavations. Thesis submitted for the degree of Doctor of Philosophy in the University of London, Department of Civil Engineering, Imperial College, London.

4 Vollum, R.L., Izzuddin, B.A., Abela, J.M. \& Potts, D.M., Blinding Struts - Part 2: Simplified Design Method, submitted to Engineering Structures.

5 Martinet, A. Flambement des voies sans joints sur ballast et rails de grande longeur. Revue Générale des Chemins de Fer, 55, 1936, 212-230. 
6 Kerr, A. D., On the stability of railroad track in the vertical plane. Rail International, 5, 1974, 131-142.

7 Kerr, A.D. and Dallis, W.A., Blow-up of concrete road pavements. J. Transp. Eng., $1985,111,33-53$.

8 Croll, J. G. A., Thermal buckling of pavement slabs. Transport Journal of the Proc. ICE, 158 TR2, 2005, 115-126.

9 Hobbs, R. E., Pipeline buckling caused by axial loads. J. Constructional. Steel Research, 1 (2), 1981, 2-10.

10 Croll, J. G. A. (1997) A simplified model of the upheaval buckling of subsea pipelines. Thin Walled Structures, 29, 59-78.

11 Croll, J. G. A. (1998) A simplified analysis of imperfect thermally buckled subsea pipelines. International J of Offshore and Polar Engng., 8 (4), 283-291.

12 Izzuddin, B. A. (1991) Nonlinear dynamic analysis of framed structures. Thesis submitted for the degree of Doctor of Philosophy in the University of London, Department of Civil Engineering, Imperial College, London.

13 Izzuddin, B. A. \& Elnashai, A. S. (1993) Adaptive space frame analysis Part II: a distributed plasticity approach. Proc. Instn Civ. Engrs Structs \& Bldgs., 99, 317-326.

14 Izzuddin, B. A. (2009) ADAPTIC Manual Version 1.3b, Imperial College, London http://hdl.handle.net/10044/1/4228.

15 CEB-FIP. CEB-FIP Model Code 1990, Comité Euro-International du Béton, 1993.

16 Potts, D. M. \& Zdravković, L. (2001) Finite Element Analysis in Geotechnical Engineering: Volume II-Application, Telford Publishing, London. 


\begin{tabular}{|c|c|c|c|c|c|c|c|}
\hline Parameters & Test D & Test E & Test F & Test $M$ & Test 0 & Test P† & Test Q \\
\hline Profile shape & Sinusoidal & Sinusoidal & Sinusoidal & Sinusoidal & ICFEP & ICFEP & ICFEP \\
\hline $\begin{array}{l}\text { Maximum } \\
\text { imperfection } \\
\text { amplitude }(\mathrm{mm})\end{array}$ & 8.8 & 8.8 & 6.3 & 6.3 & 6.3 & 6.3 & 6.3 \\
\hline Thickness (mm) & 52.6 & 50.0 & 55.0 & 68.0 & 54.0 & 48.0 & 60.0 \\
\hline $\begin{array}{l}\text { Concrete } \\
\text { compressive } \\
\text { strength (MPa) }\end{array}$ & 28.2 & 28.0 & 19.7 & 33.8 & 30.7 & 28.1 & 28.5 \\
\hline $\begin{array}{l}\text { Initial concrete } \\
\text { tangent modulus E } \\
(\mathrm{GPa})\end{array}$ & 25.6 & 27.7 & 29.7 & 34.6 & 29.7 & 29.1 & 28.5 \\
\hline $\begin{array}{l}\text { Concrete tensile } \\
\text { strength (MPa) }\end{array}$ & 2.3 & 2.1 & 1.7 & 2.2 & 2.1 & 2.1 & 2.2 \\
\hline \multicolumn{8}{|l|}{ Eccentricities* } \\
\hline Loading End (mm) & 4.1 & 2.3 & 5.3 & 4.0 & 5.1 & 11.5 & 1.5 \\
\hline Reaction End (mm) & 2.2 & 4.1 & 4.9 & 2.0 & 4.8 & 10.0 & 0.0 \\
\hline \multicolumn{8}{|l|}{ End Conditions } \\
\hline Loading End & Pin & Pin & Pin & Pin & Pin & Pin & Fixed \\
\hline Reaction End & $\begin{array}{l}\text { Lifted by } \\
5 \mathrm{~mm}\end{array}$ & $\begin{array}{l}\text { Lifted by } \\
1.7 \mathrm{~mm}\end{array}$ & Pin & Pin & Pin & Pin & Fixed \\
\hline $\begin{array}{l}\text { Age at loading } \\
\text { (days after casting) }\end{array}$ & 18 & 16 & 14 & 14 & 14 & 14 & 15 \\
\hline Failure load (kN) & 335 & 336 & 240 & 440 & 412 & 412 & 465 \\
\hline $\begin{array}{l}\text { Predicted failure } \\
\text { load }(k N)\end{array}$ & $202^{\S}$ & $202^{\S}$ & 245 & 448 & 410 & $592^{*}$ & 477 \\
\hline
\end{tabular}

Note: * The eccentricity is measured upwards from the centroid of the strut. + The ends of strut $P$ were tapered as shown in Fig. 14. The eccentricities are measured relative to the centroid of the unreduced cross-section depth of $48 \mathrm{~mm}$ in test $P$. $\S$ Calculated assuming ends prevented from lifting. * Calculated neglecting the reduction in cross section at the ends of the strut.

Table 1: Details of tested struts

\begin{tabular}{|l|c|c|c|c|c|c|c|}
\hline$x / L$ & 0 & 0.025 & 0.05 & 0.075 & 0.1 & 0.15 & 0.2 \\
$\mathrm{w}(\mathrm{x}) / \mathrm{w}_{\mathrm{g}}$ & 0 & 0.384 & 0.676 & 0.8 & 0.842 & 0.882 & 0.922 \\
$\mathrm{x} / \mathrm{L}$ & 0.25 & 0.3 & 0.35 & 0.4 & 0.45 & 0.5 & - \\
$\mathrm{w}(\mathrm{x}) / \mathrm{w}_{\mathrm{g}}$ & 0.95 & 0.967 & 0.984 & 0.992 & 0.996 & 1 & - \\
\hline
\end{tabular}

Notes: $\mathrm{X} / \mathrm{L}=$ normalised distance along strut

Table 2: Normalised ICFEP profile 


\section{List of Figures}

Figure 1: Schematic diagram of excavation process for cantilever retaining wall Figure 2: Upheaval buckling of blinding strut

Figure 3: Buckled shapes for blinding struts with a) load applied below centroid and b) load applied above centroid with left hand end free to lift

Figure 4: Model of strut in ADAPTIC

Figure 5: Nonlinear concrete model con1 used in ADAPTIC

Figure 6: The experimental setup a) Plan view of rig, b) Section A - Left hand side, and Section B - Right hand side, c) View of internal reaction frame and supports used to adjust strut profile and $d$ ) blinding strut in test rig

Figure 7: Schematic diagram of loading arrangement at strut end with wedge Figure 8: Strut at end of test

Figure 9: Comparison of initial (sinusoidal), measured and predicted displaced shapes of the blinding struts in Tests $\mathrm{F}$ and $\mathrm{M}$ immediately before failure

Figure 10: Axial load versus a) axial displacement and b) transverse displacement at centre of strut displacement in Tests $F$ and $M$

Figure 11: Comparison of initial (ICFEP), measured and predicted displaced shapes of the blinding struts in Tests $\mathrm{O}$ and $\mathrm{Q}$ immediately before failure

Figure 12: Axial load versus a) transverse displacement at one eighth of the strut length from each end and $b$ ) axial displacement in Test $O$

Figure 13: Load versus a) transverse displacement at one eighth of the strut length from each end and $b$ ) axial displacement in Test $Q$

Figure 14: Schematic diagram of strut end showing wedges and end thickness reduction

Figure 15: Comparison of initial (ICFEP profile), measured and predicted transverse displaced shapes in Test $P$ immediately before failure

Figure 16: Load versus displacement at a) one quarter span from each end of strut, b) one eighth span from each end of strut and $c$ ) axial displacement for Test $P$

Figure 17: Comparison of measured and predicted displaced shapes in Tests $D$ and $E$ immediately before failure

Figure 18: Load versus a) transverse displacement at the centre of the strut and b) axial displacement for Tests $\mathrm{D}$ and $\mathrm{E}$

Figure 19: Buckled shapes for a) sinusoidal, b) parabolic and c) ICFEP ground profiles considered

Figure 20: Influence on the buckling load of a $20 \mathrm{~m}$ long strut of a) imperfection amplitude for a $200 \mathrm{~mm}$ thick strut and b) strut thickness for an imperfection amplitude of $100 \mathrm{~mm}$.

Figure 21: Effect of the eccentricity of the axial load within the cross-section depth 


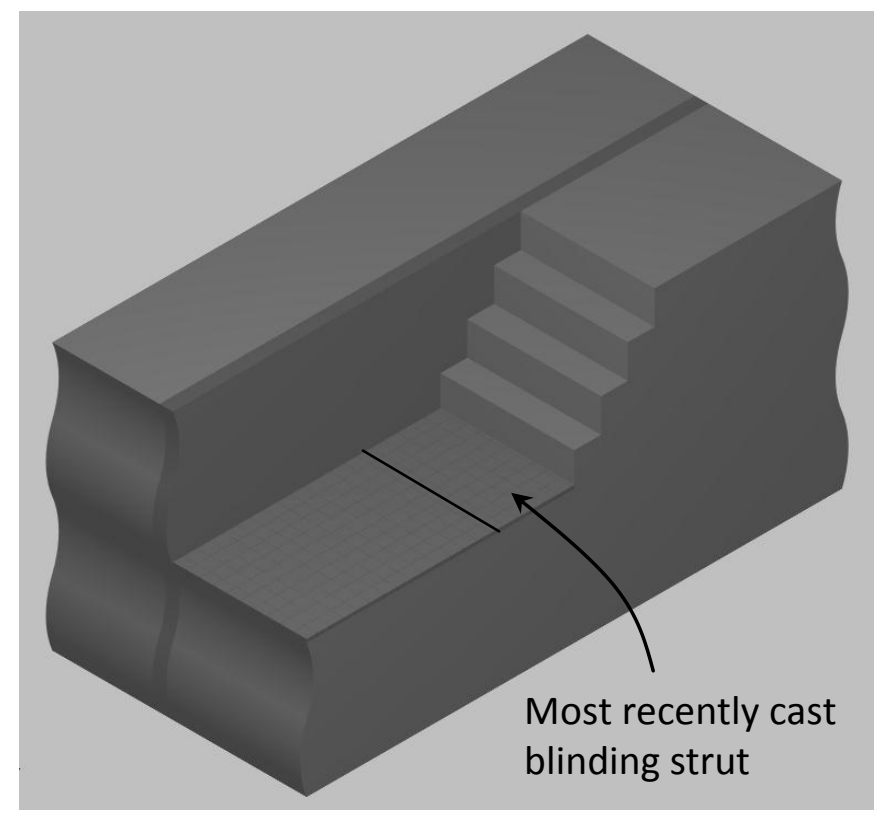

Figure 1: Schematic diagram of excavation process for cantilever retaining wall 


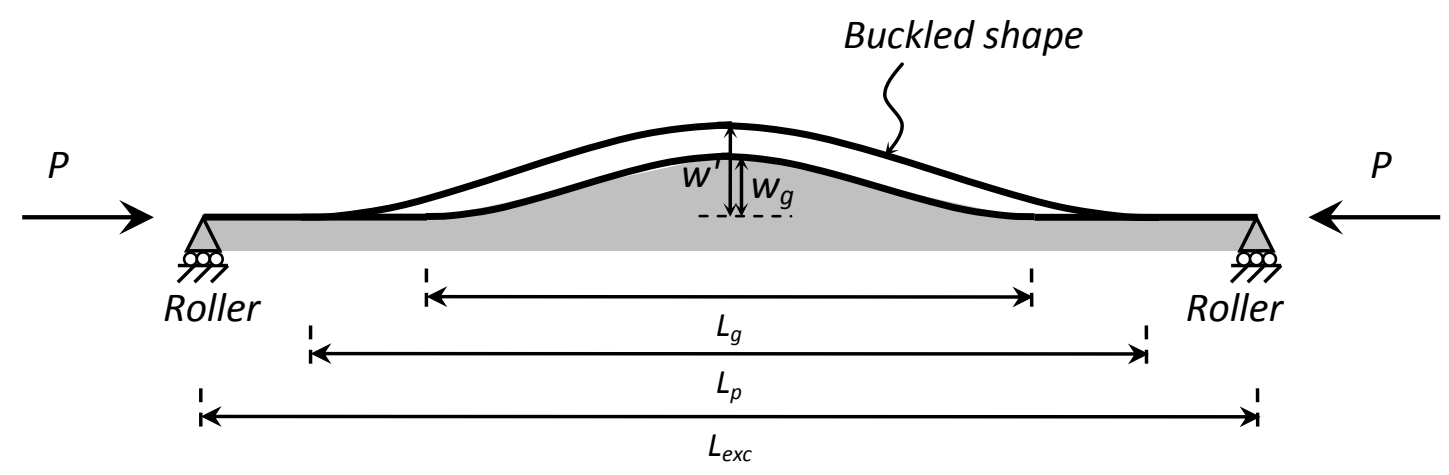

Figure 2: Upheaval buckling of blinding strut 


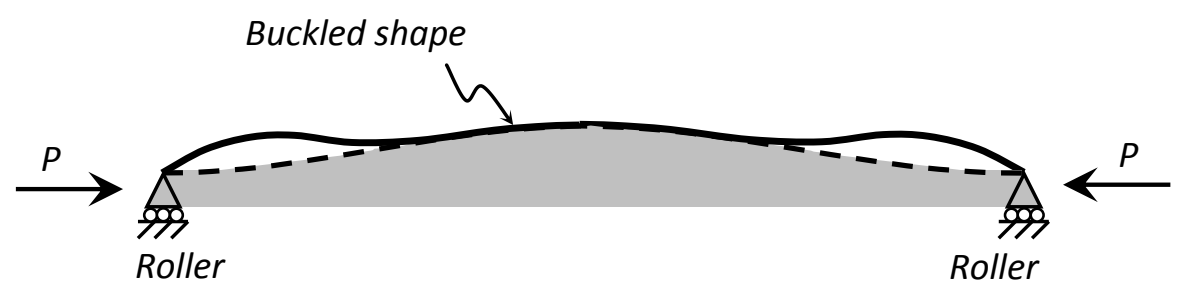

a)

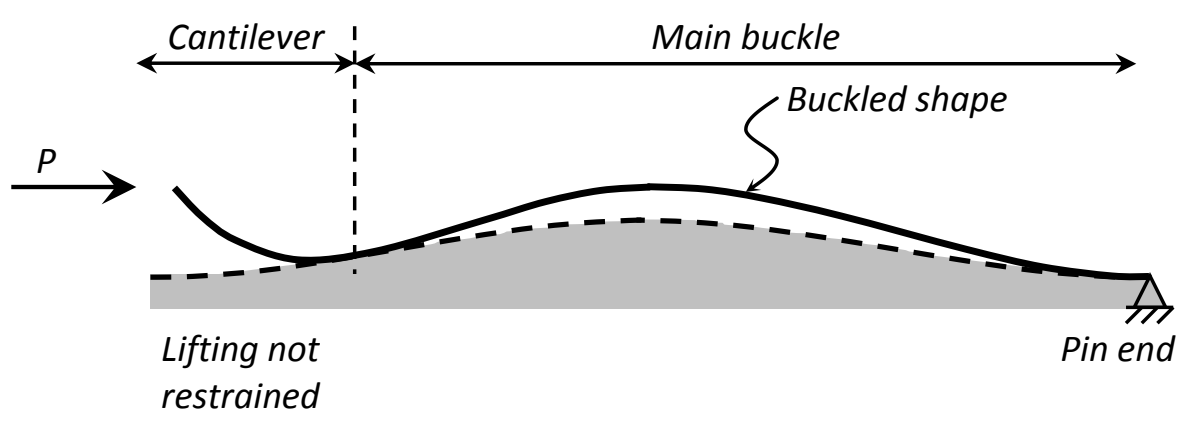

b)

Figure 3: Buckled shapes for blinding struts with a) load applied below centroid and b) load applied above centroid with left hand end free to lift 


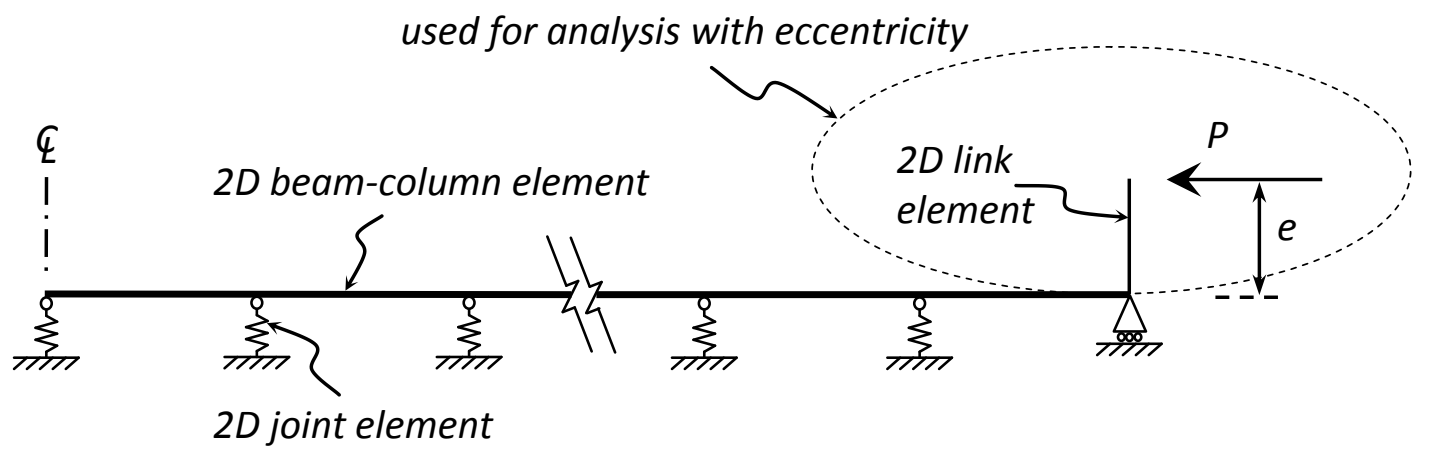

Figure 4: Model of strut in ADAPTIC 


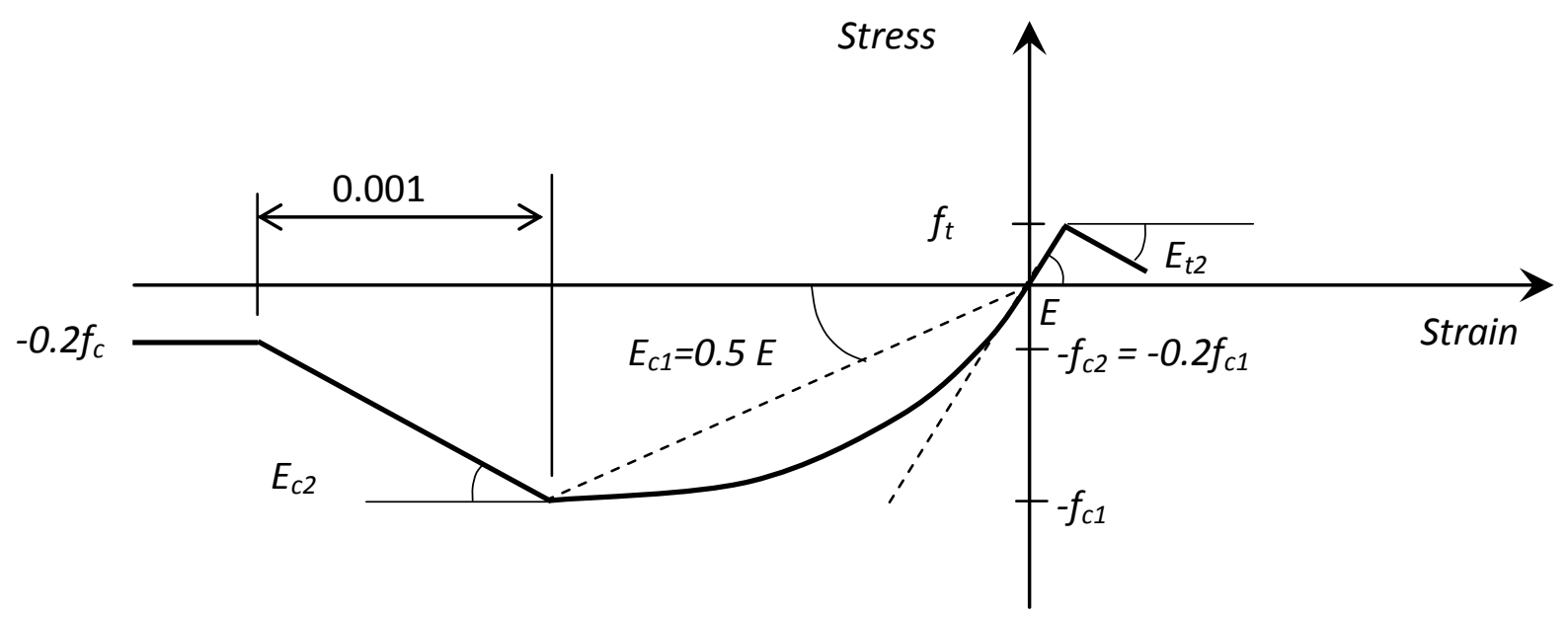

Figure 5: Nonlinear concrete model con1 used in ADAPTIC 


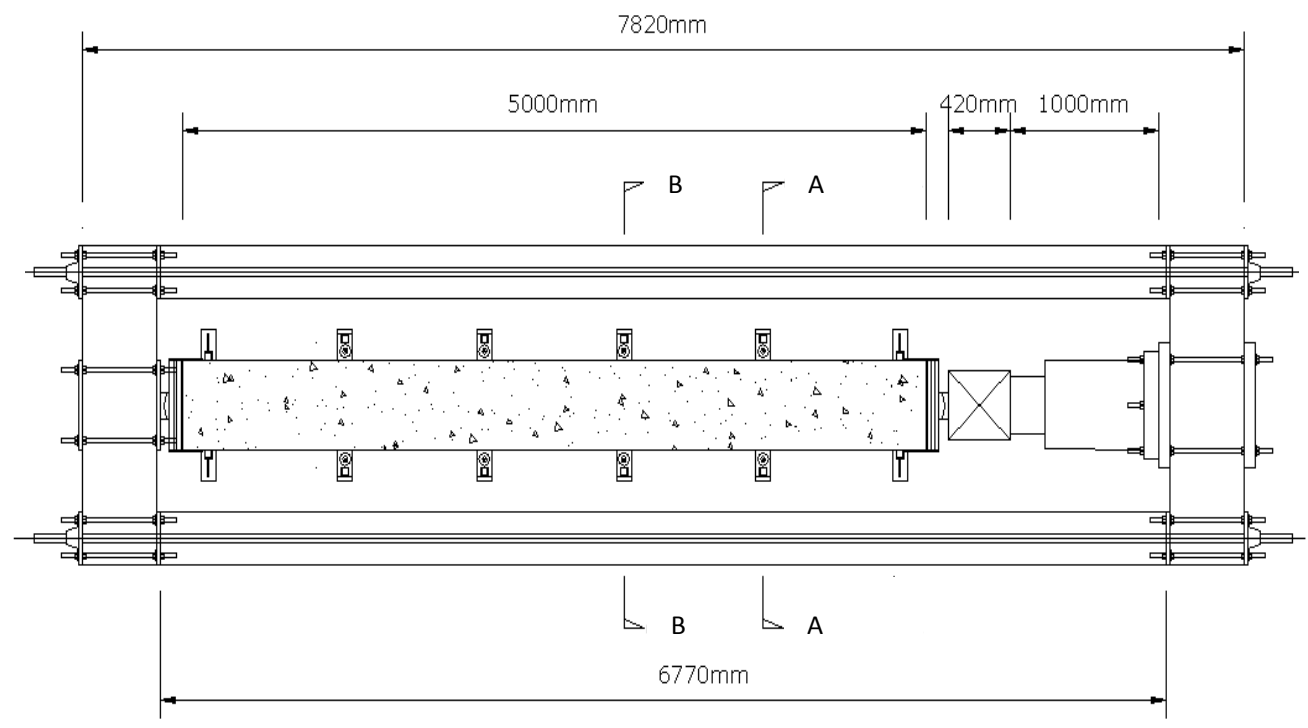

a)

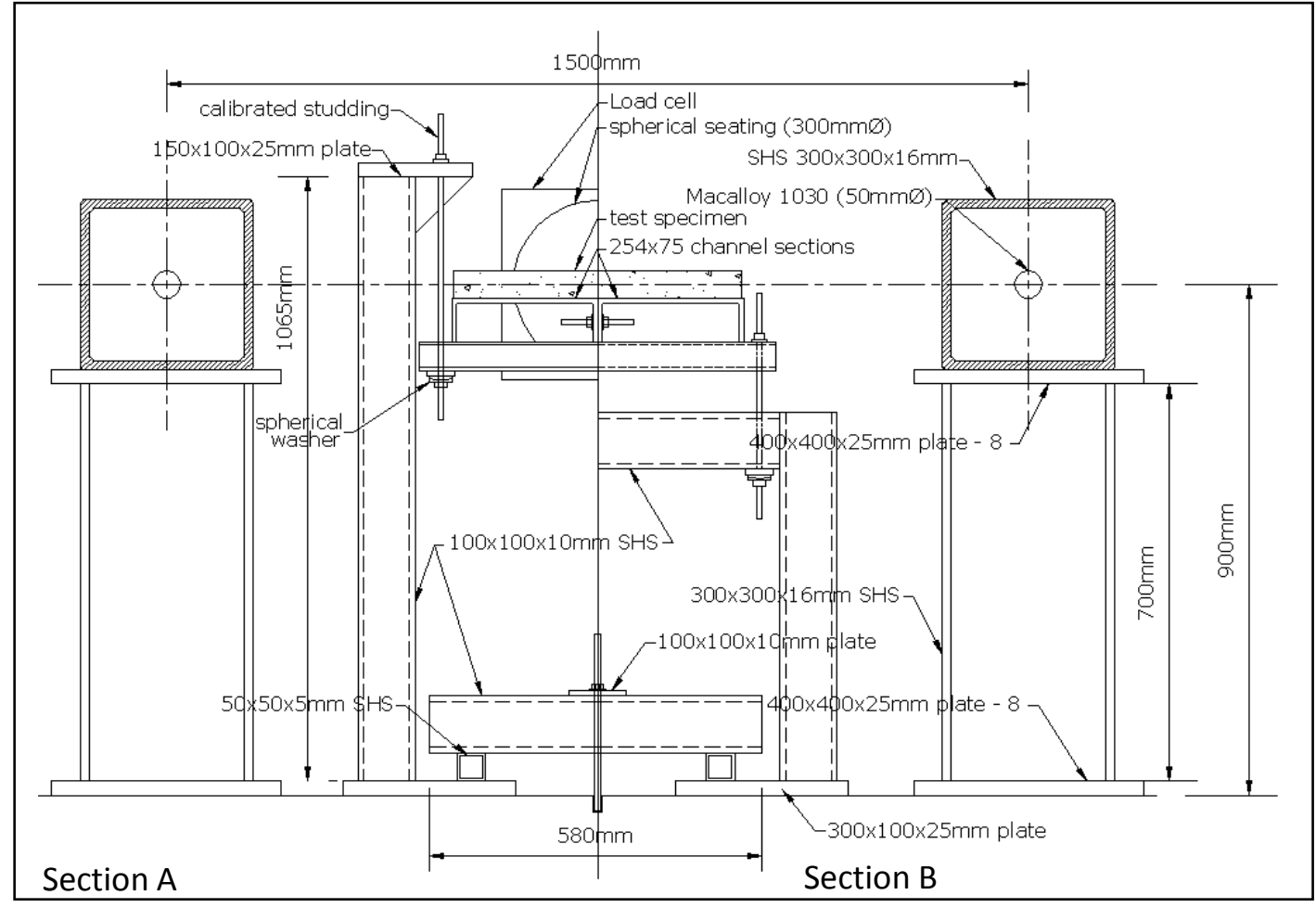

b) 


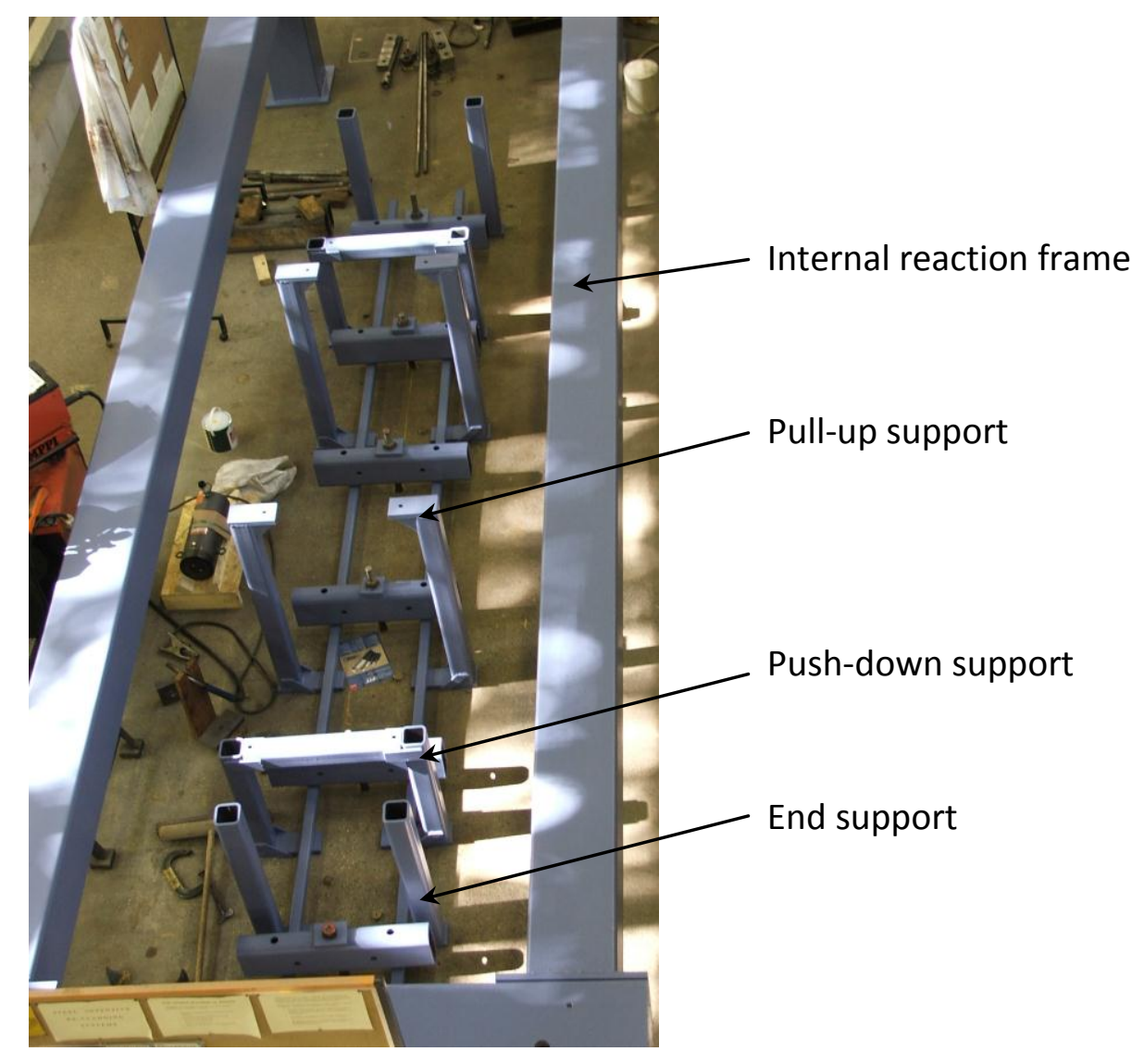

c)

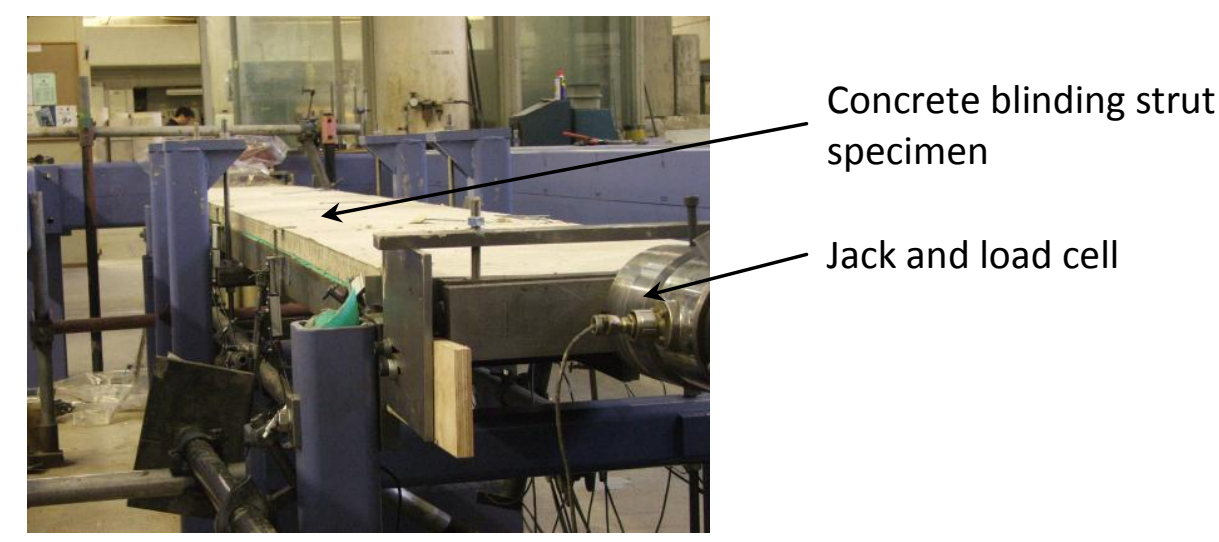

d)

Figure 6: The experimental setup a) Plan view of rig, b) Section A - Left hand side, and Section B - Right hand side, c) View of internal reaction frame and supports used to adjust strut profile and $d$ ) blinding strut in test rig 


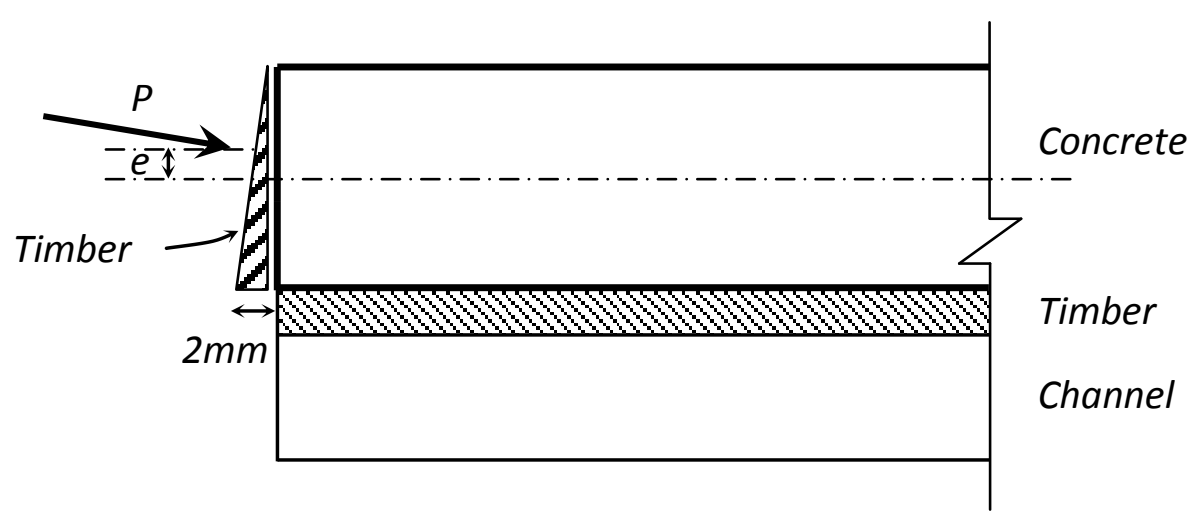

Figure 7: Schematic diagram of loading arrangement at strut end with wedge 


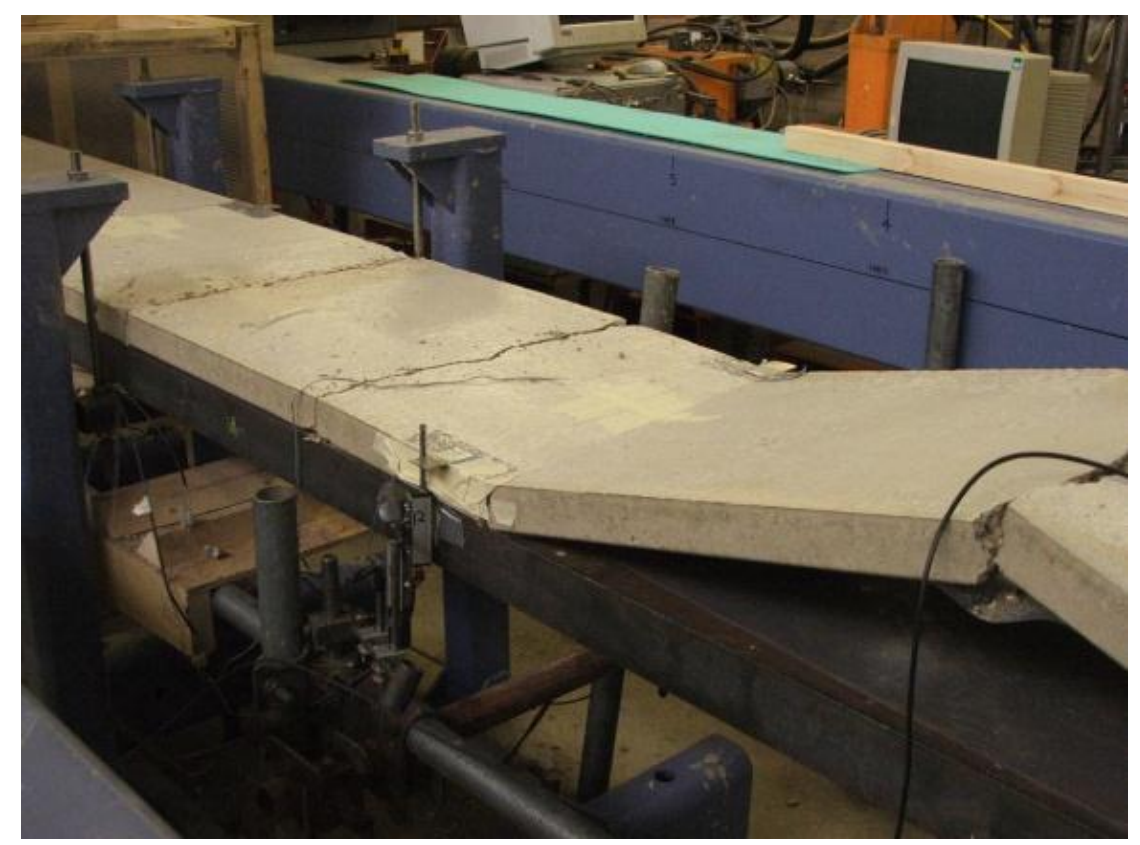

Figure 8: Strut at end of test 


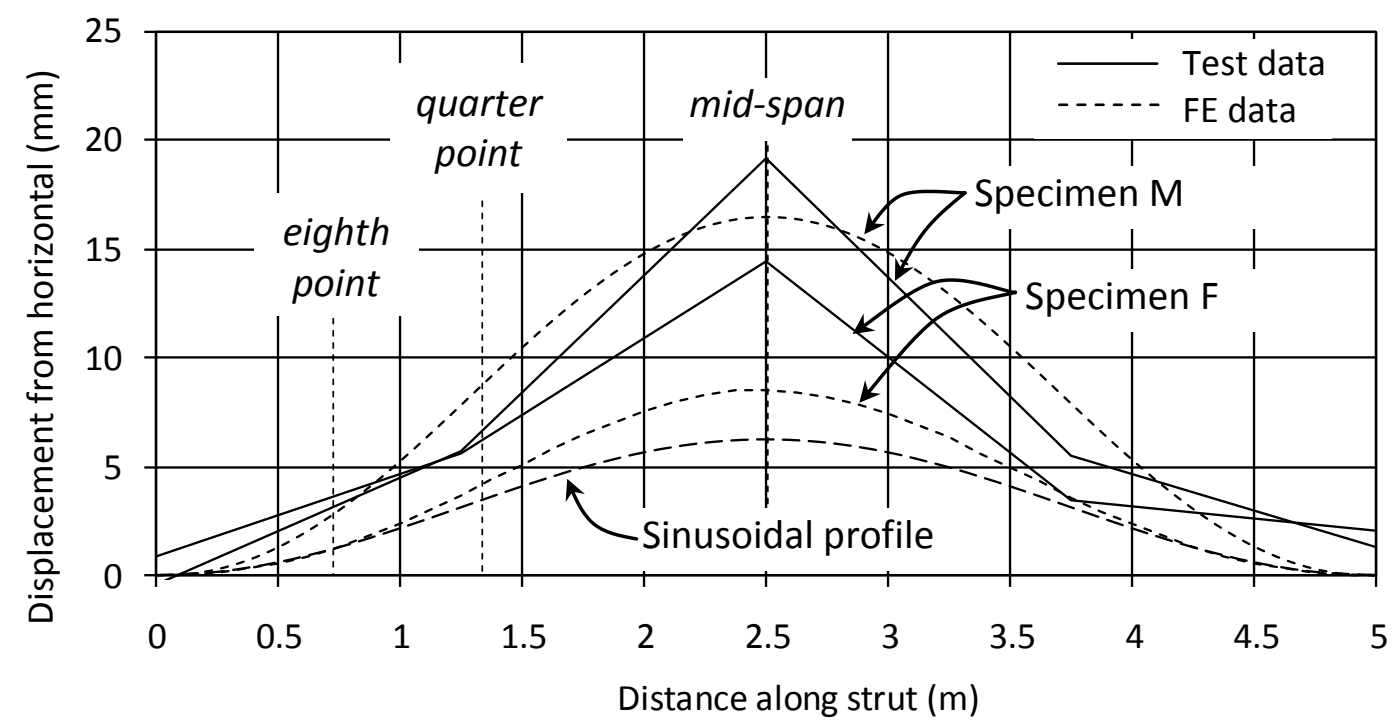

Figure 9: Comparison of initial (sinusoidal), measured and predicted displaced shapes of the blinding struts in Tests $\mathrm{F}$ and $\mathrm{M}$ immediately before failure 


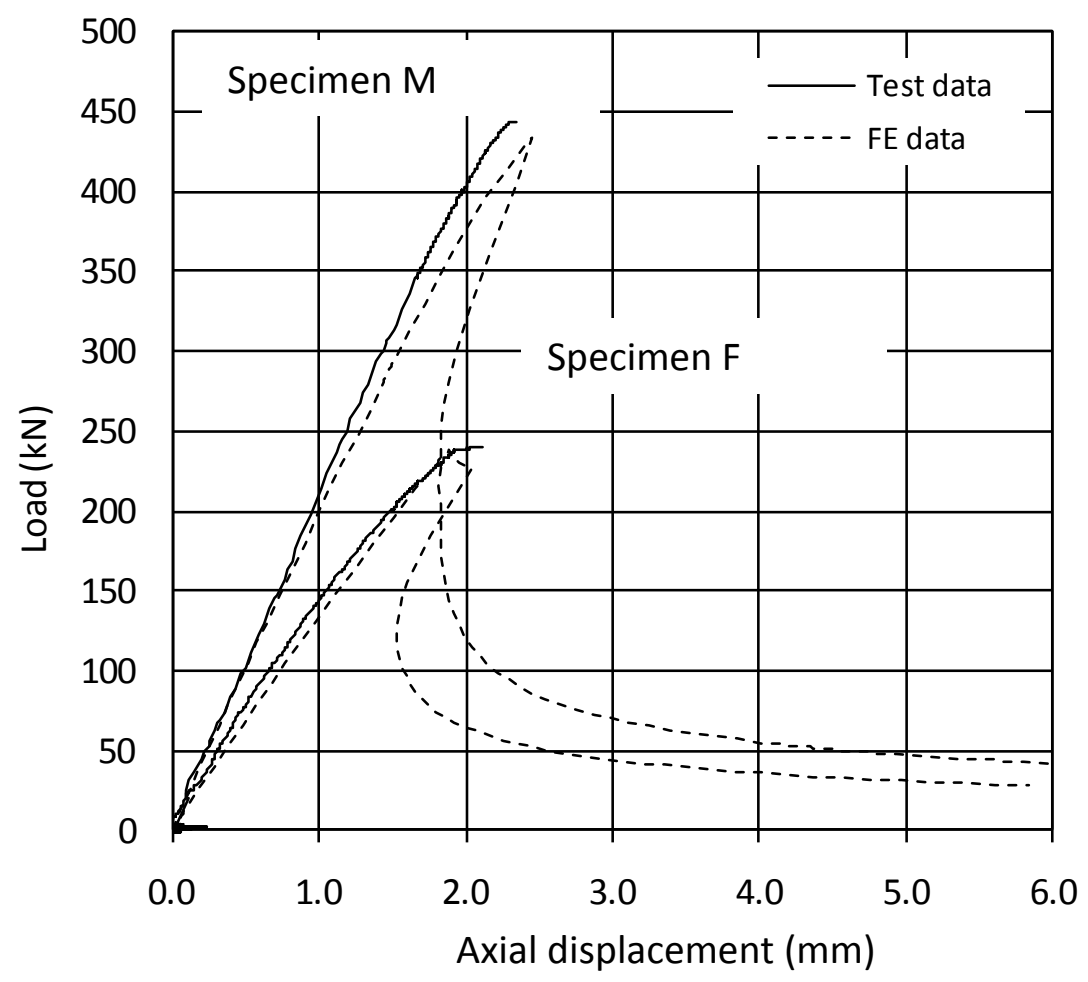

(a)

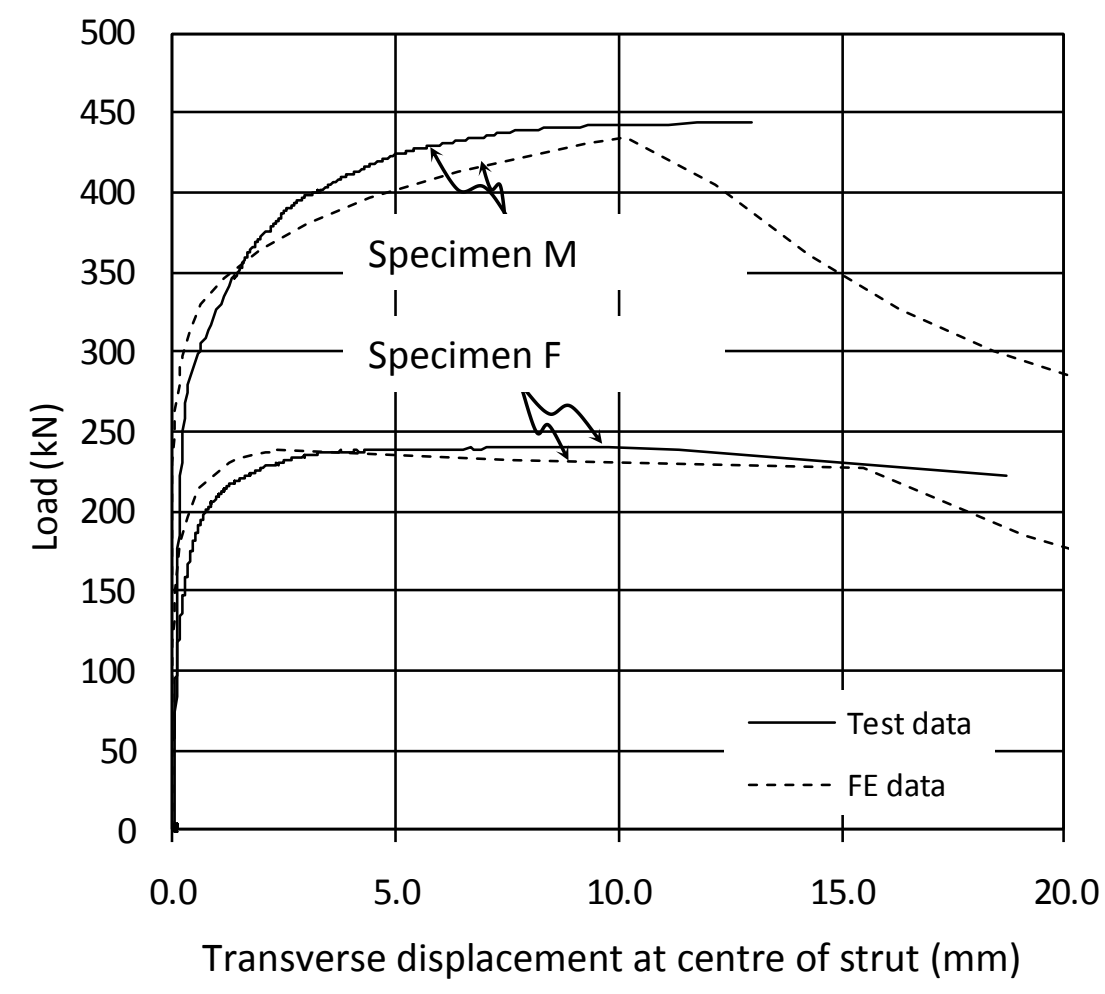

b)

Figure 10: Axial load versus a) axial displacement and b) transverse displacement at centre of strut displacement in Tests $F$ and $M$ 


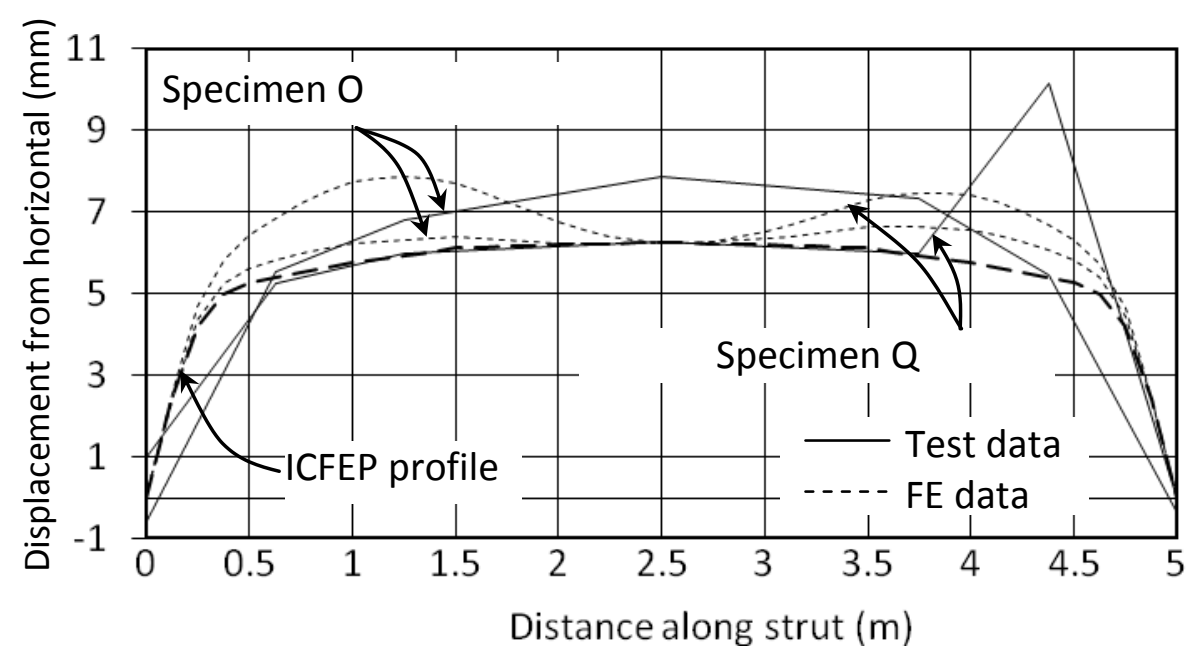

Figure 11: Comparison of initial (ICFEP), measured and predicted displaced shapes of the blinding struts in Tests $\mathrm{O}$ and $\mathrm{Q}$ immediately before failure. 


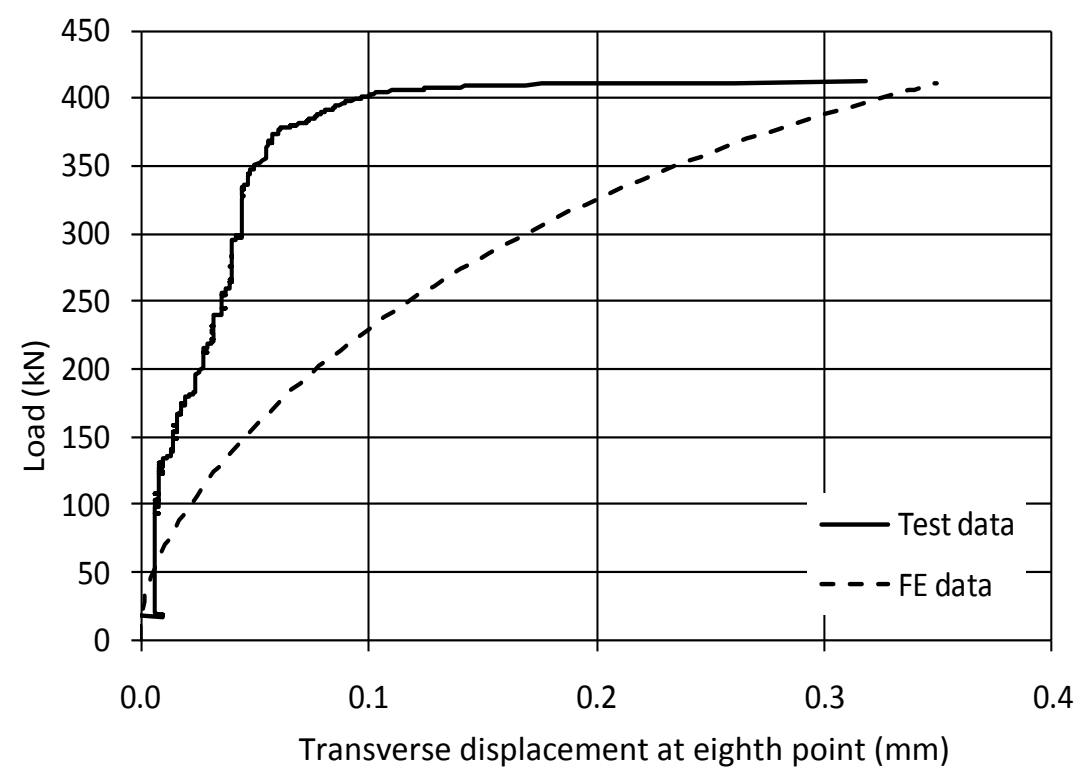

a)

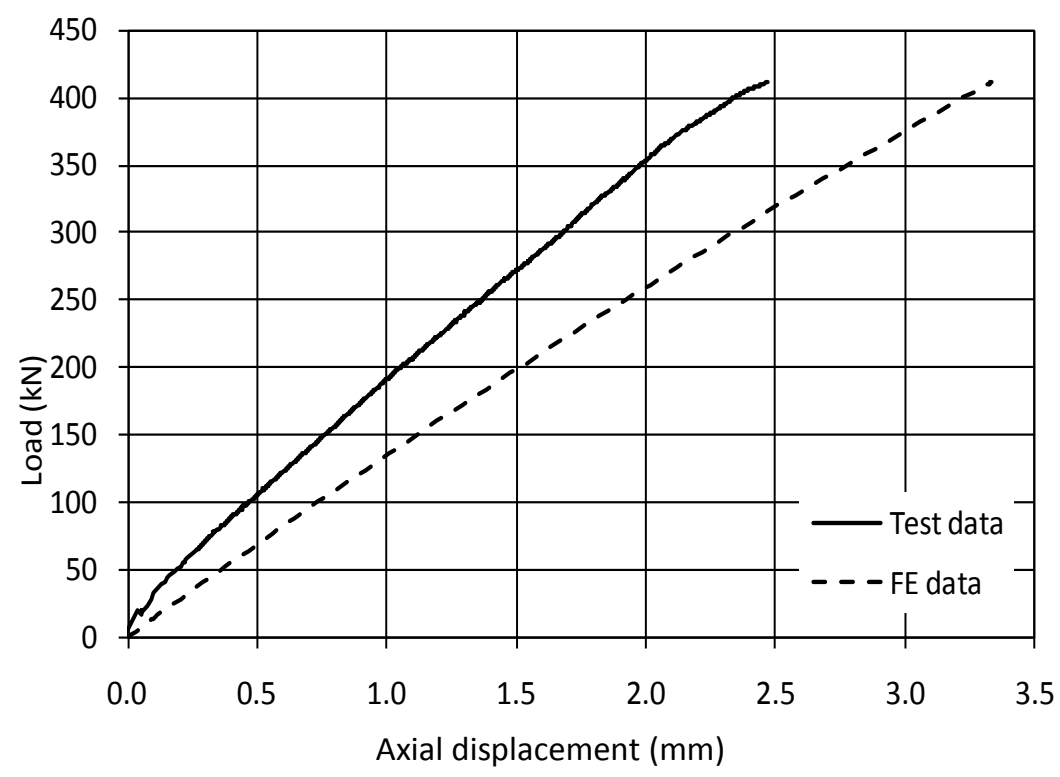

b)

Figure 12: Axial load versus a) transverse displacement at one eighth of the strut length from each end and b) axial displacement in Test $O$ 


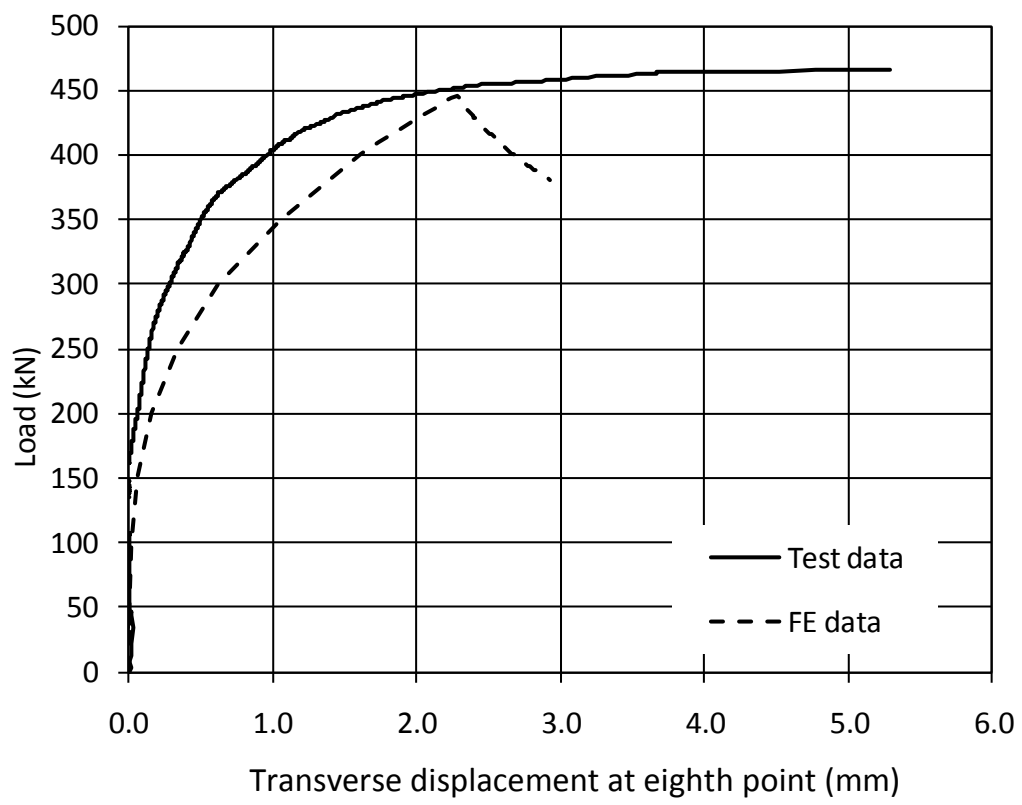

a)

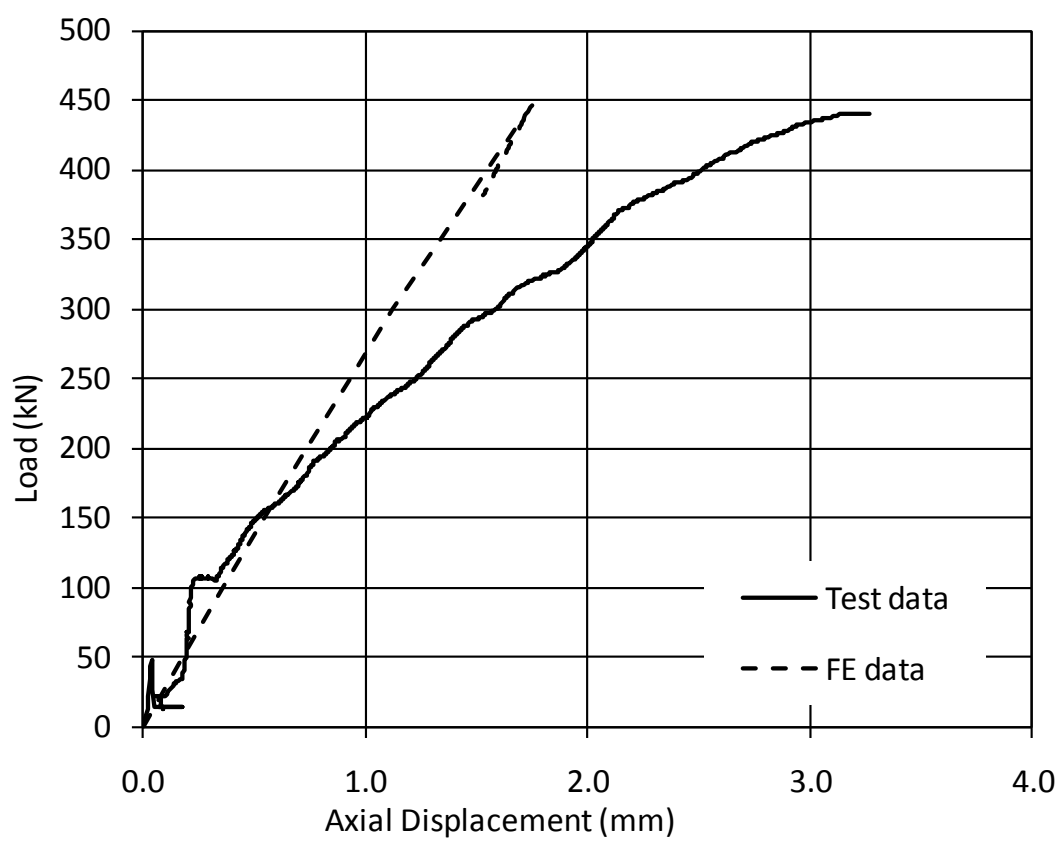

b)

Figure 13: Load versus a) transverse displacement at one eighth of the strut length from each end and $b$ ) axial displacement in Test $Q$ 


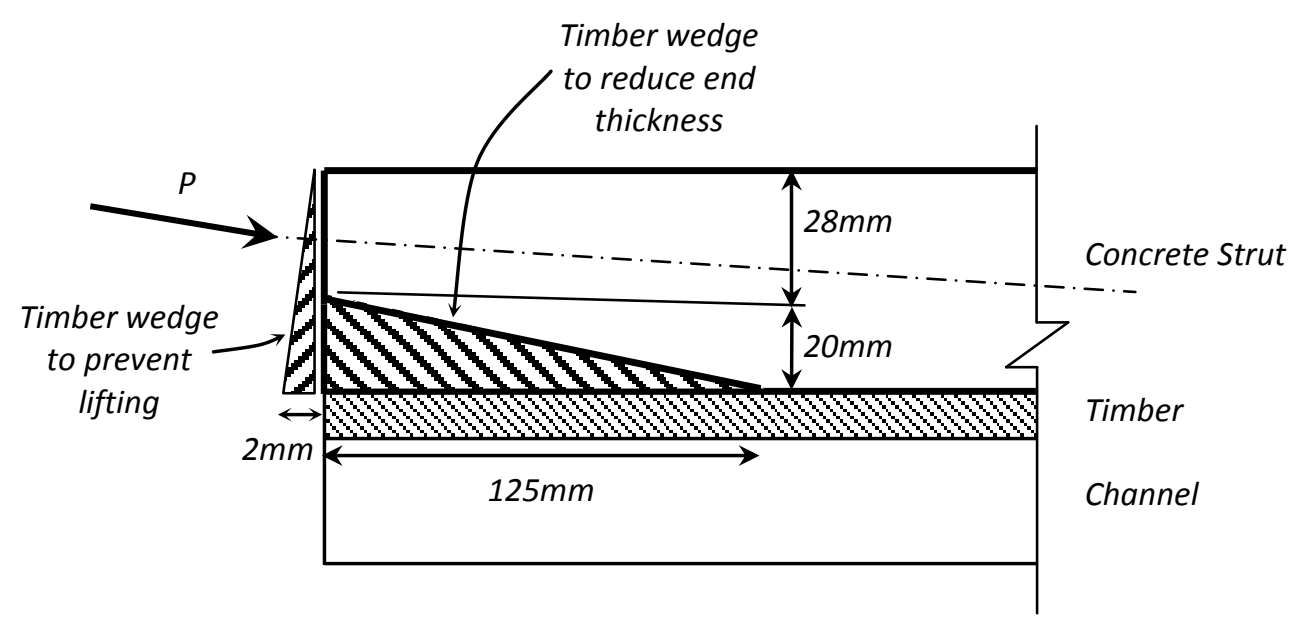

Figure 14: Schematic diagram of strut end showing wedges and end thickness reduction 


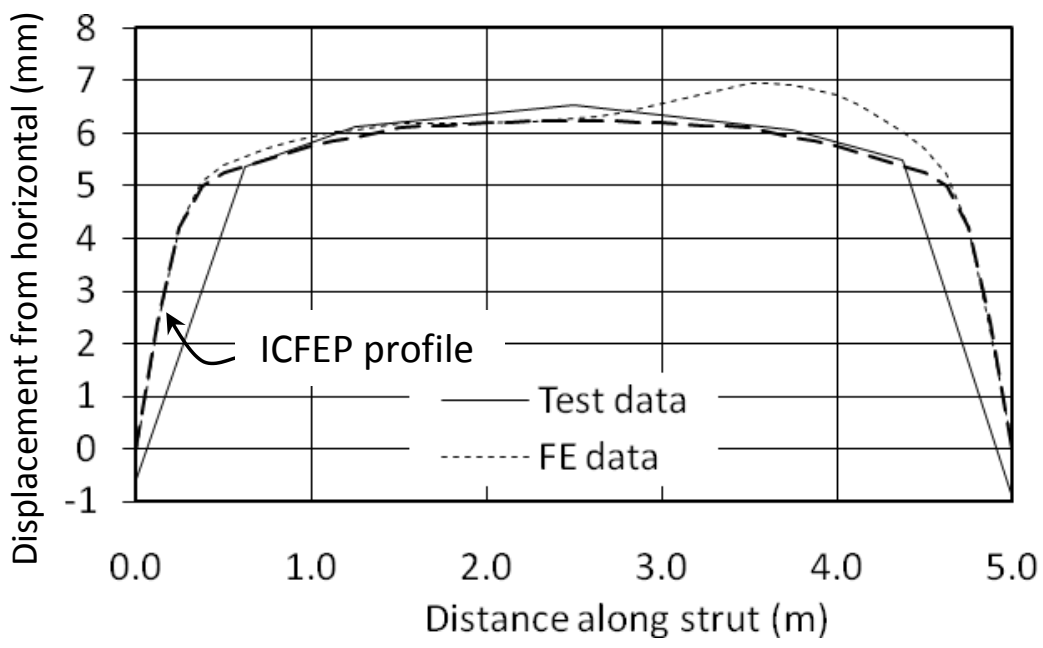

Figure 15: Comparison of initial (ICFEP profile), measured and predicted transverse displaced shapes in Test P immediately before failure. 


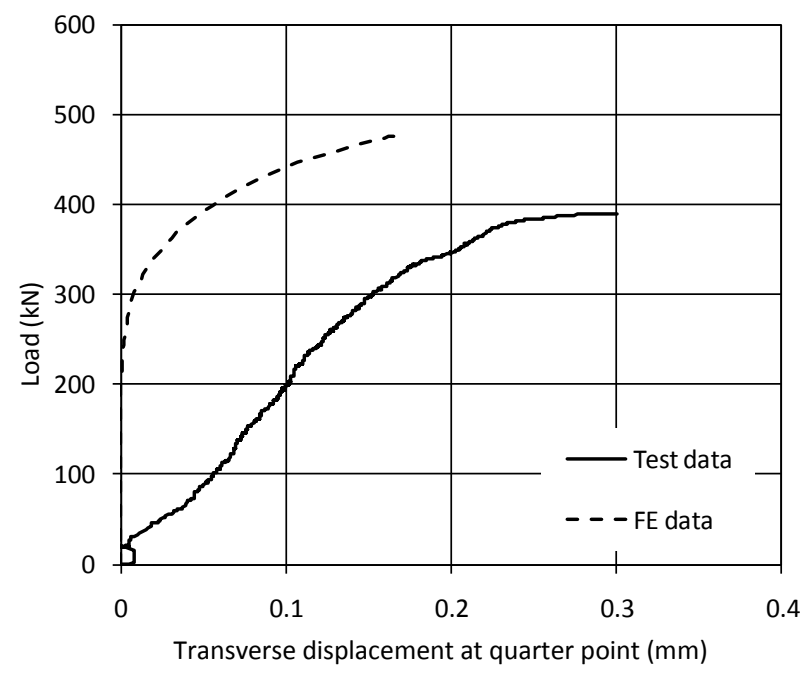

a)

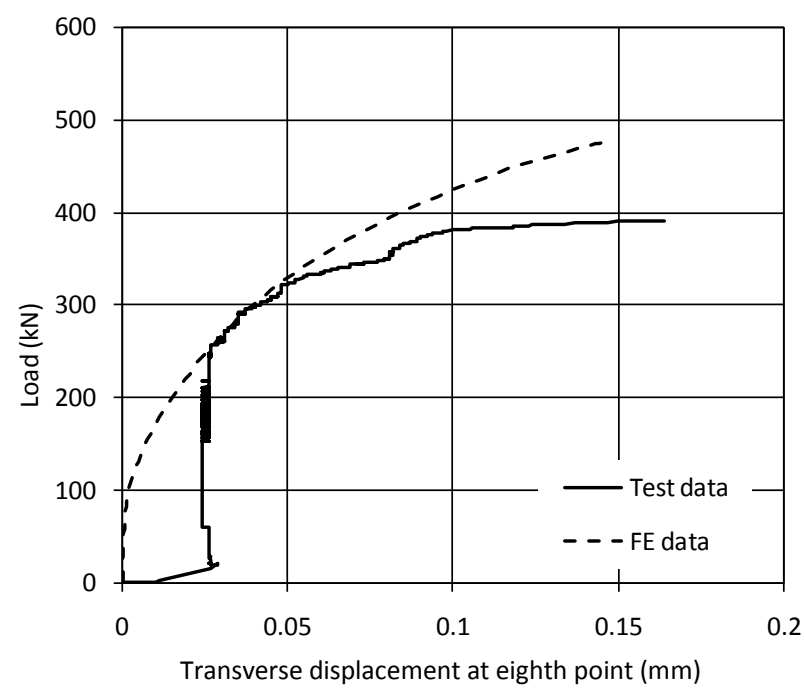

b)

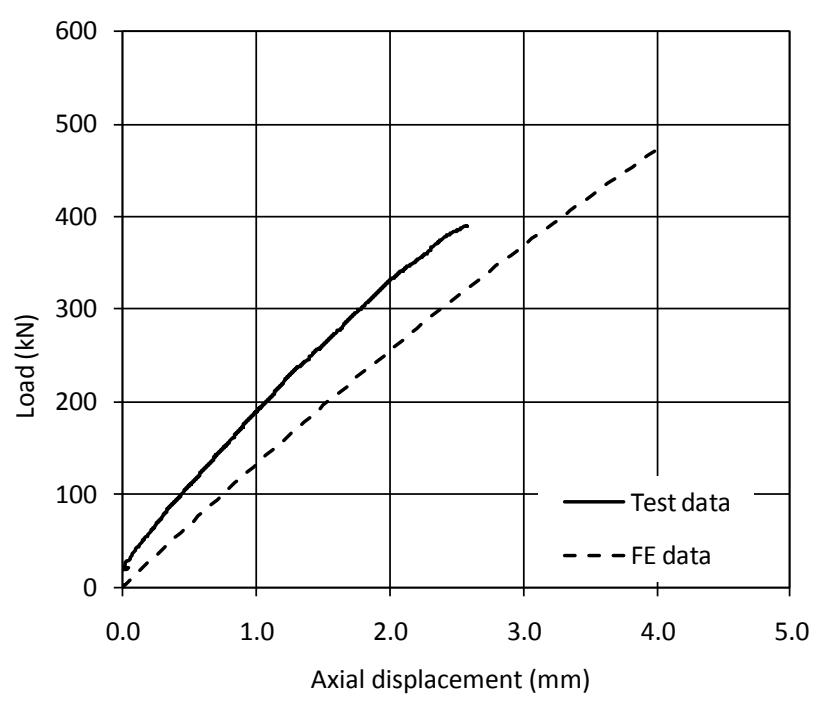

c)

Figure 16: Load versus displacement at a) one quarter span from each end of strut, $b$ ) one eighth span from each end of strut and c) axial displacement for Test $P$ 


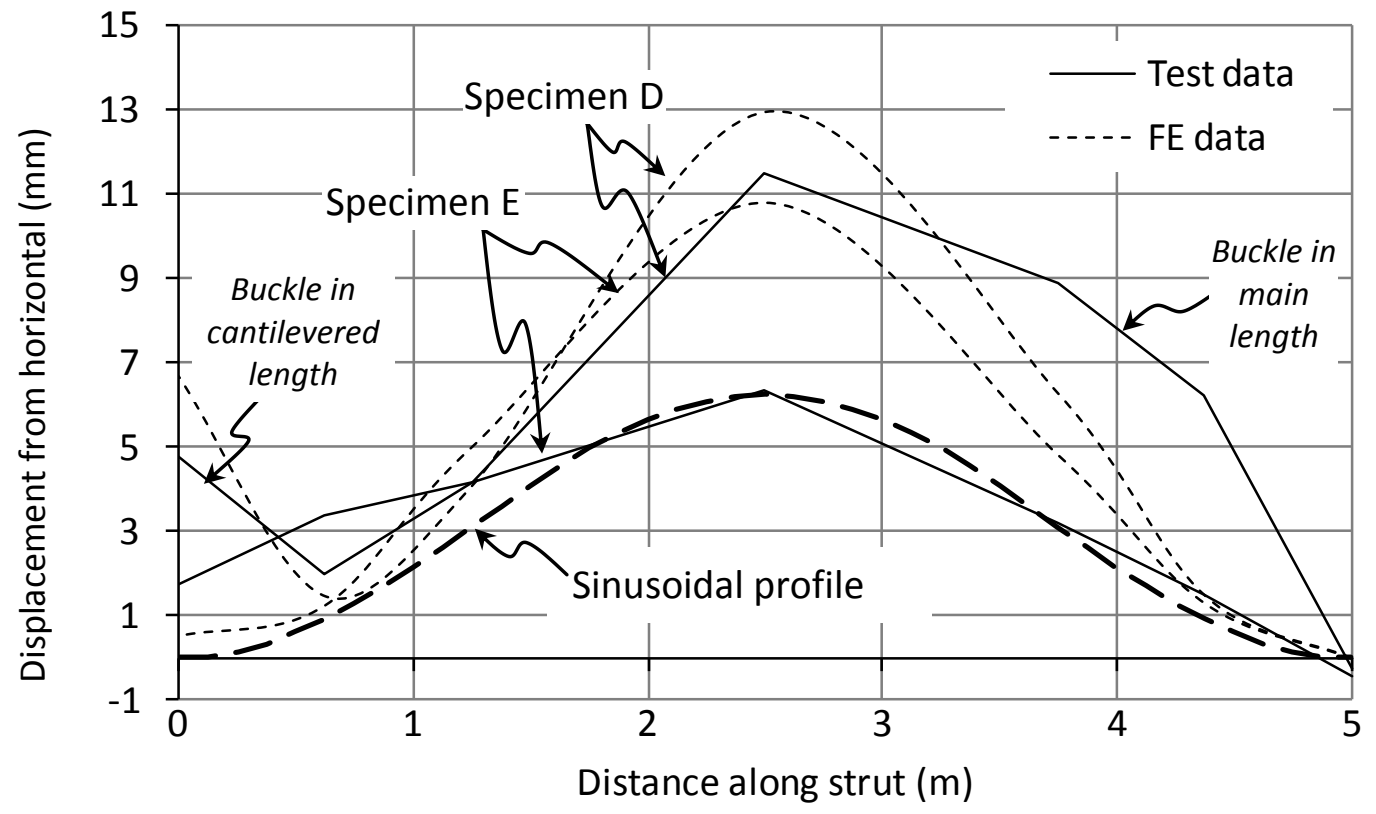

Figure 17: Measured and predicted displaced shapes of the blinding struts in Tests $D$ and $E$ at failure 


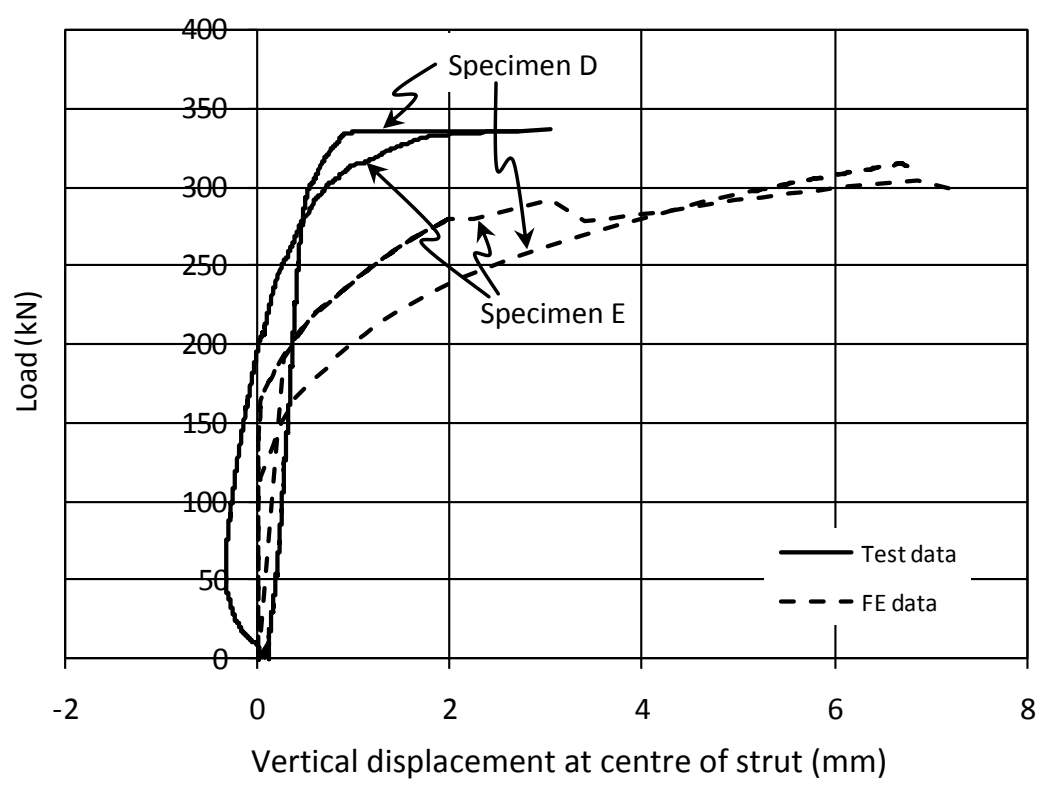

a)

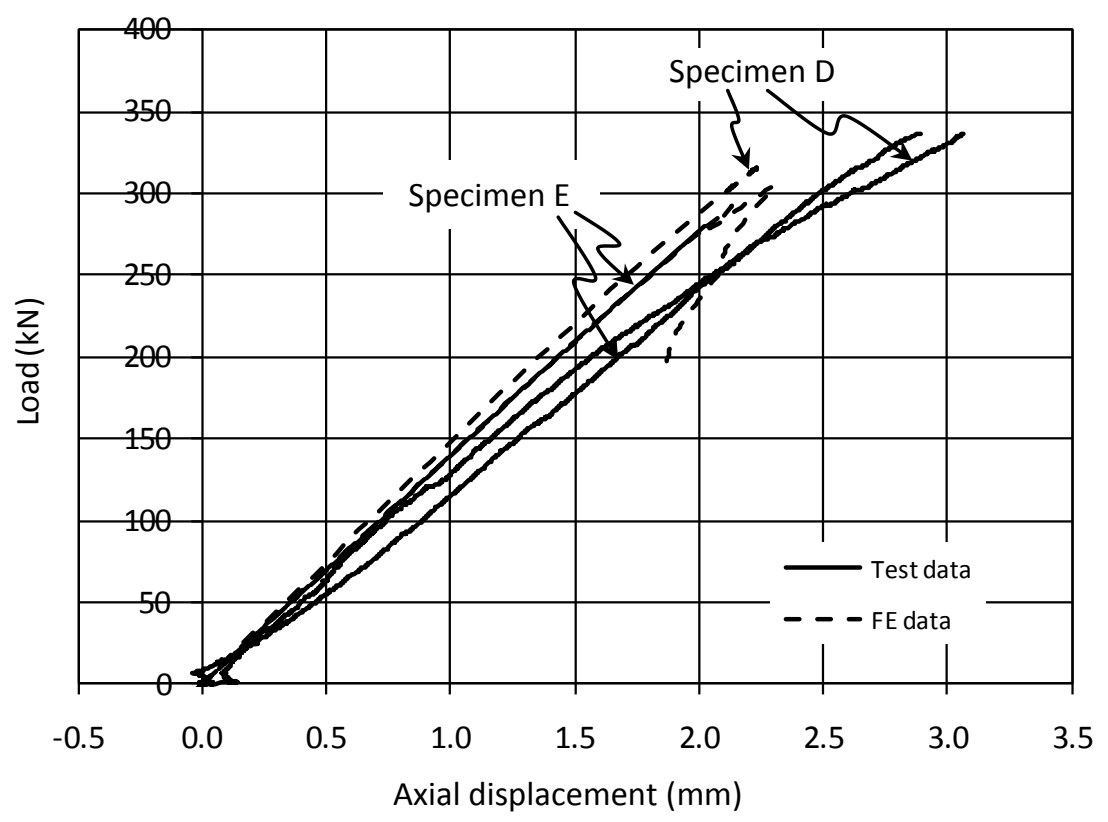

b)

Figure 18: Load versus displacement at a) the centre of the strut and b) axial displacement for Tests $D$ and $E$ 


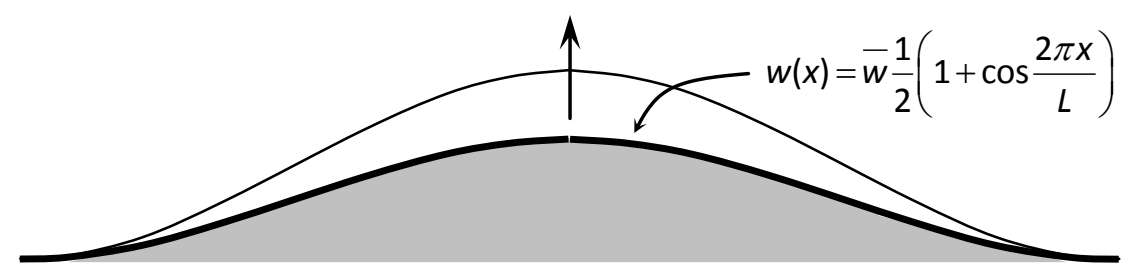

a)

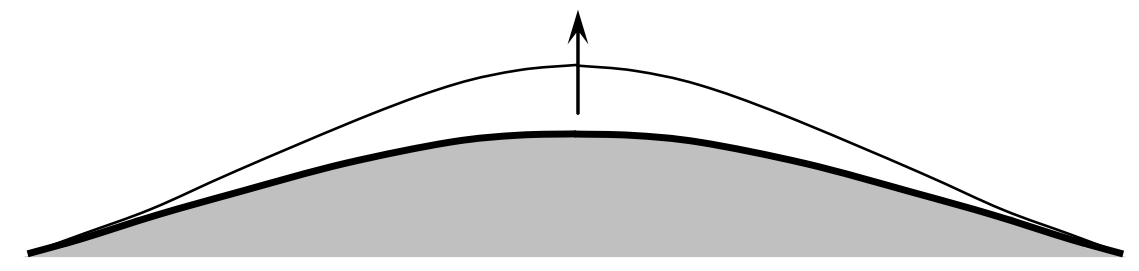

b)

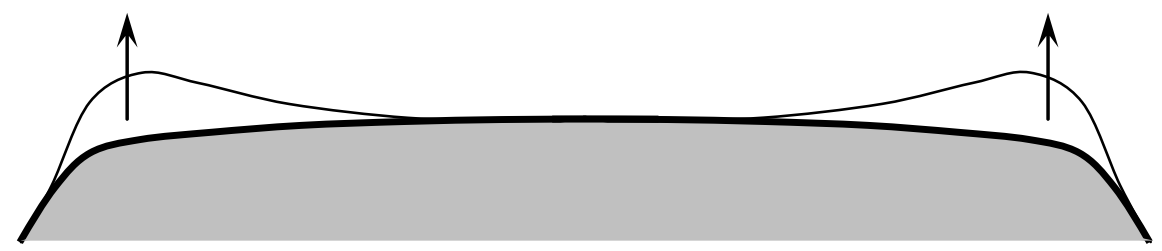

c)

Figure 19: Buckled shapes for a) sinusoidal, b) parabolic and c) ICFEP ground profiles considered 


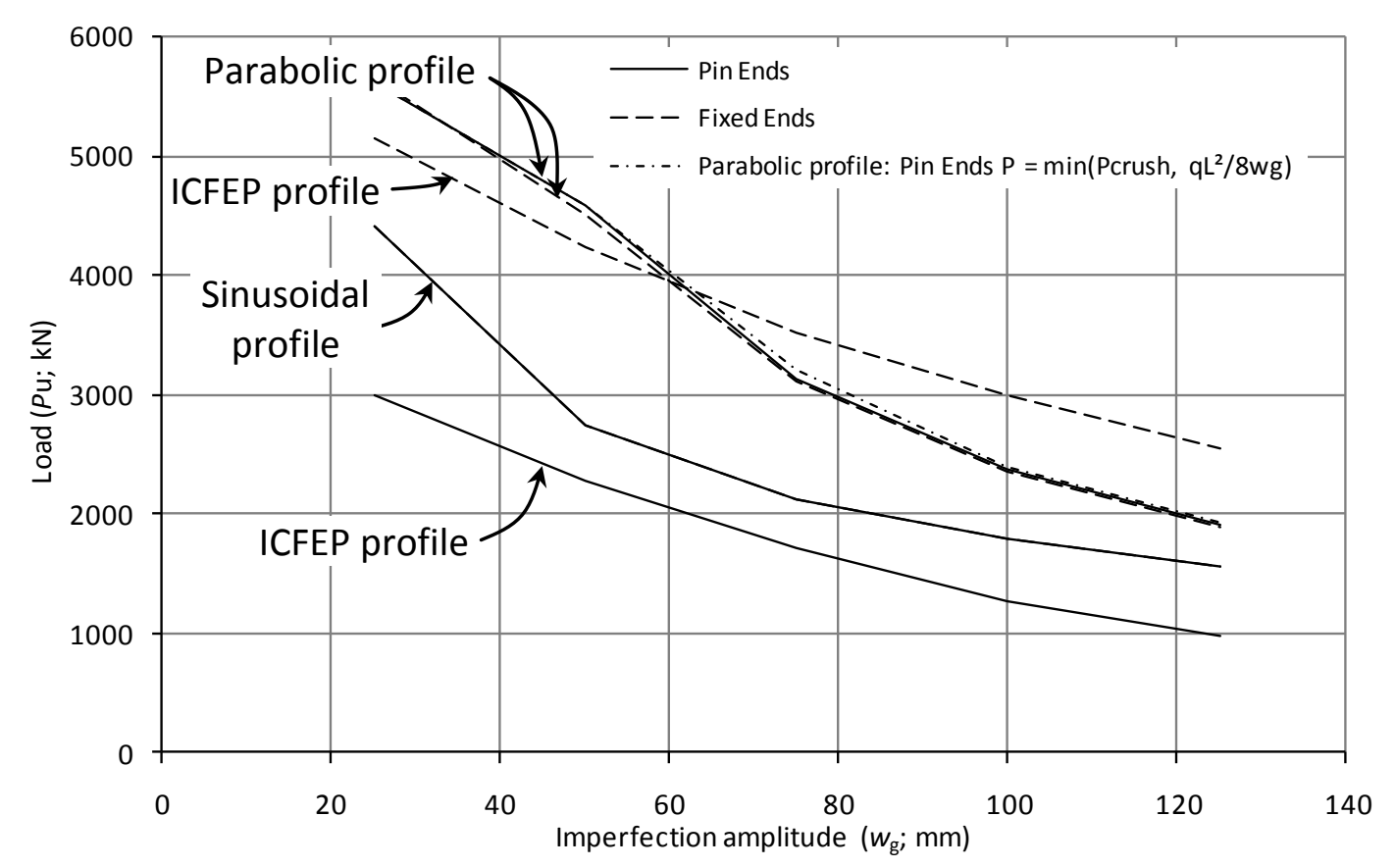

a)

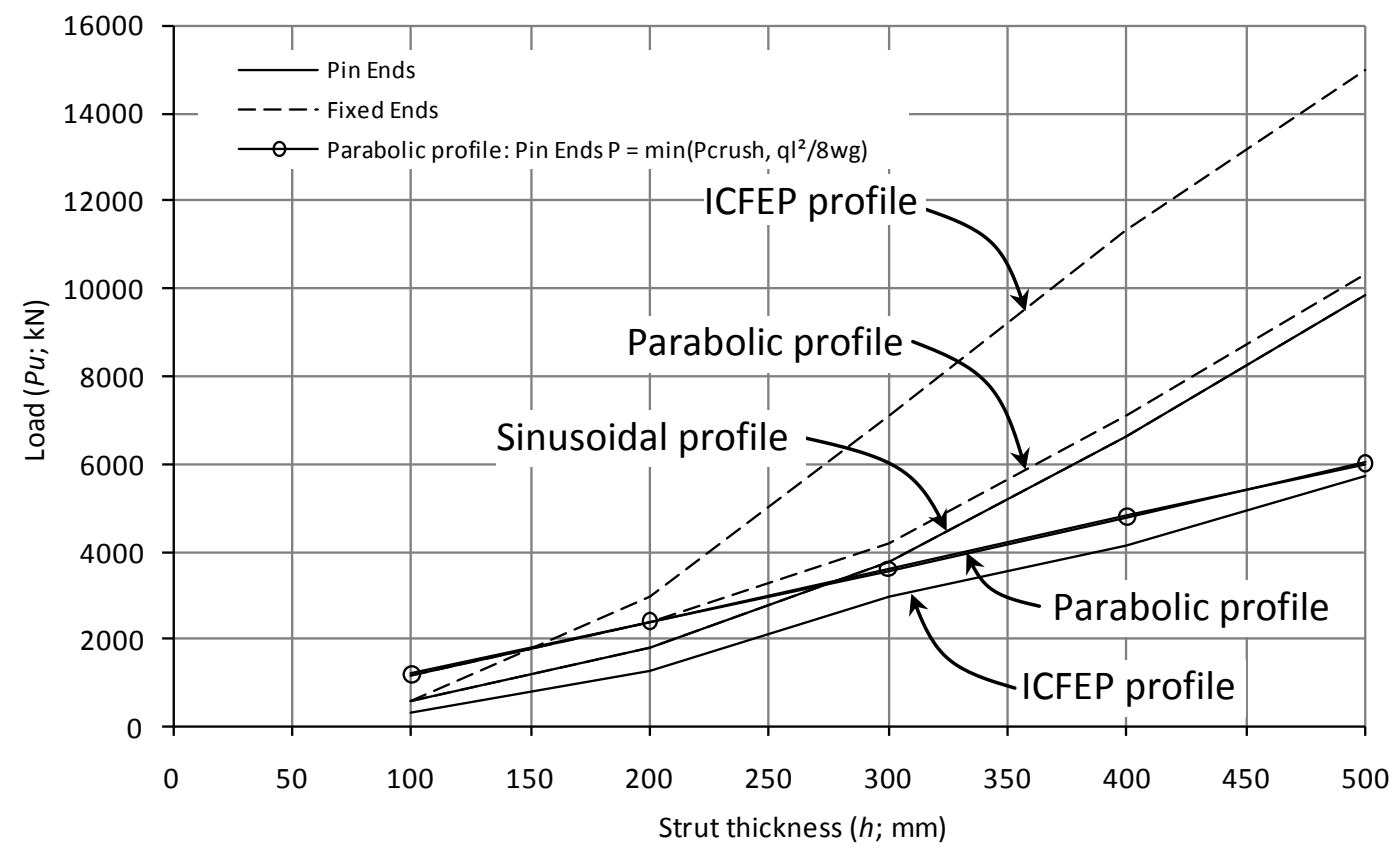

b)

Figure 20: Influence on the buckling load of a $20 \mathrm{~m}$ long strut of a) imperfection amplitude for a $200 \mathrm{~mm}$ thick strut and b) strut thickness for an imperfection amplitude of $100 \mathrm{~mm}$. 

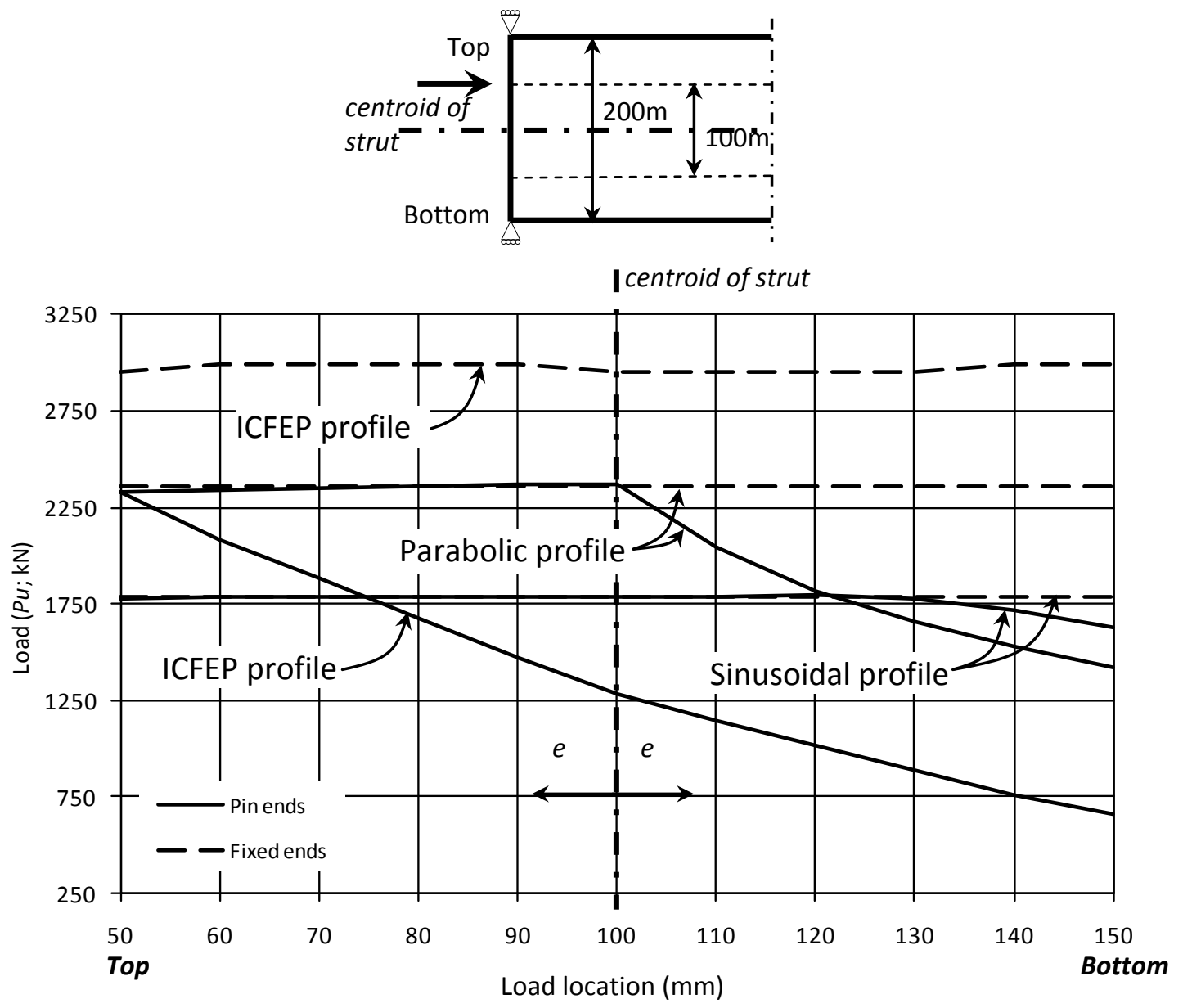

Figure 21: Effect of the eccentricity of the axial load within the cross-section depth 